\title{
Seismic Velocities in Mantle Minerals and the Mineralogy of the Upper Mantle
}

\author{
Thomas S. Duffy and Don L. Anderson
}

\author{
Seismological Laboratory, California Institute of Technology, Pasadena, California
}

\begin{abstract}
Comparison of seismic velocities in mantle minerals, under mantle conditions, with seismic data is a first step toward constraining mantle chemistry. The calculation, however, is uncertain due to lack of data on certain physical properties. "Global" systematics have not proved very useful in estimating these properties, particularly for the shear parameters. A new approach to elasticity estimation is used in this study to produce estimates of unknown quantities, primarily pressure and temperature derivatives of elastic moduli, from the structural and chemical trends evident in the large amount of elasticity data now available. These trends suggest that the derivatives of unmeasured high-pressure phases can be estimated from "analogous" low-pressure phases. Using these predictions and the best available measurements, seismic velocities are computed along high-temperature adiabats for a set of mantle minerals using third-order finite strain theory. The calculation of density and moduli at high temperature, to initiate the adiabat, must be done with care since parameters such as thermal expansion are not independent of temperature. Both compressional and shear seismic profiles are well-matched by a mineralogy dominated by clinopyroxene and garnet and with an olivine content of approximately $40 \%$ by volume. Between 670 and 1000 $\mathbf{k m}$, perovskite alone provides a good fit to the seismic velocities. Combining seismic velocities with recent phase equilibria data for a hypothetical pure olivine mantle suggests that a mineralogy with a maximum of $35 \%$ olivine (shear profile) or $40-53 \%$ olivine (compressional profile) by volume can satisfy the constraint imposed by the $400 \mathrm{~km}$ discontinuity. Other features of the upper mantle can then be matched by appropriate combinations of pyroxenes, garnets, and their high-pressure equivalents. While mantle models with a substantially larger fraction of olivine cannot be ruled out, they are acceptable only if the derivatives of the spinel phases are substantially different from olivine and deviate from trends in the larger data set.
\end{abstract}

\section{INTRODUCTION}

The mantle represents $68 \%$ of the mass of the Earth. The chemistry of this region, if known, would represent a major constraint on the current structural, compositional, thermal, and dynamical state of the planet and its evolution to the present state. Despite a large volume of work on the subject, the chemistry of the mantle has not been unambiguously resolved. This paper will focus on the upper mantle (above $670 \mathrm{~km}$ ) and attempt to evaluate the state of upper mantle mineralogy, primarily from the point of view of elasticity data and equations of state.

Seismic profiles yield detailed information about elastic preperties that may be compared to laboratory measured properties. The primary limitation of this approach is that many of the elastic properties required for such a comparison have not been measured. In particular, pressure and temperature derivatives of elastic moduli for many high-pressure phases are unknown. In view of the difficulty associated with synthesizing large single crystals of these phases, these properties are likely to remain unknown for some time to come. To date, most investigators have estimated the unknown properties without adopting any systematic scheme for doing so, and their conclusions about the composition of the transition zone are difficult to justify.

Comparison of seismological and laboratory-based elasticity data dates back to Birch [1952]. In more recent years, studies which have discussed this problem include Ander-

Copyright 1989 by the American Geophysical Union.

Paper number 88JB03880

0148-0227/89/88JB-03880\$05.00 son [1967, 1970], Burdick and Anderson [1975], Lees et al. [1983], Bass and Anderson [1984], Weidner [1986, 1987], Anderson and Bass [1986], and Bina and Wood [1987]. A slightly different approach, extrapolating seismologically determined parameters to stand ard $\mathrm{T}$ and $\mathbf{P}$ conditions for comparison with laboratory data, was discussed by Butler and Anderson [1978] and Jeanloz and Krittle [1986]. In addition to sound speeds, density can also be obtained from the inversion of seismic data, albeit with low resolution, and compared to mineral assemblages [Bass and Anderson, 1984; Jeanloz and Knittle, 1986; Liu and Bassett, 1986]. The problem has also been addressed from a petrological perspective by Jeanloz and Thompson [1983], Irifune [1987], and Akaogi et al. [1987].

Despite the large body of work on the subject, a consensus has failed to emerge. Debate has focused on two primary mineralogical models: the pyrolite model [Ringwood, 1975] and the eclogite or piclogite model [Bass and Anderson, 1984; Anderson and Bass, 1986]. The pyrolite model is dominated by olivine and orthopyroxene with these two minerals accounting for about $\mathbf{7 5 \%}$ of the assemblage by volume. The range of compositions encompassing the piclogite model is such that the eclogite component (clinopyroxene and garnet) is dominant and the olivine content is less than $50 \%$ by volume. One way to discriminate between these models is to determine which best matches the seismic velocity increase at $400 \mathrm{~km}$. This is a sensitive indicator of the olivine content of the mantle since the 400-km discontinuity is generally believed to be related to a spinel transformation in olivine [e.g., Anderson, 1967, 1970]. Another important discriminant is the high observed seismic gradient in the transition region $(400-670 \mathrm{~km})$. The absolute value of the velocities above $400 \mathrm{~km}$ can be matched 
by either model, especially in view of the trade-off with temperature [Anderson and Bass, 1984].

With this background in mind, several goals for this project may be identified. First, we need to assemble an up-to-date compilation of experimental data on the elastic properties of mantle minerals. The elasticity data set is growing at such a rate that compilations which are only 3 or 4 years old are out of date. Thus there is a need to incorporate new data into existing compilations. Data have accumulated over the last 30 years on a wide range of mineral structures and compositions. The depth and breadth of this data set is crucial as a proving ground for new elasticity estimation schemes.

The second goal is to evaluate methods of estimating the pressure and temperature derivatives of elastic moduli in a systematic way. A powerful new technique in this regard involves dimensionless logarithmic anharmonic (DLA) parameters [Anderson, 1988]. The basic theme of our approach is that any estimated quantity should be consistent with trends evident in the large elasticity data base discussed above. It may not be surprising that our estimated values are similar to measured properties of materials of similar chemistry and structure, but this is not true of several recent studies. Thus it becomes important to identify the best elastic analogues for a given material. Anomalously high or low values of derivatives are frequently used for unmeasured materials in other studies of this type. On the basis of our work, extreme values can no longer be tolerated unless they can be justified and suitably placed in the framework of the existing elasticity data set. The measurements of pressure and temperature derivatives on materials of direct relevance to the Earth are few. In total such data exist for only about seven silicates which include the olivine structure, the garnet structure, quartz, and pyroxene. There are many more measurements on oxides and other ionic solids. When this larger data base is examined, it is possible to see trends with ionic radius, chemistry, coordination, and so on that can then be applied to the silicates.

A further goal of this study is to compute the effect of temperature and pressure on the moduli, thereby facilitating computation of seismic velocities under upper mantle conditions. An extension of the method of Burdick and Anderson [1975] is used for calculating the effect of temperature. The results will be compared to other schemes to ascertain the importance of the method of computation. We point out the importance of taking into account the temperature dependence of the thermal expansion.

In assessing the implications of our work on the mineralogy of the upper mantle, we will stop short of a complete petrological inversion since our purpose is to focus on the role of elasticity data in constraining mantle mineralogy. Constraints may still be obtained by restricting consideration to the olivine system [e.g., Anderson, 1967; Bina and Wood, 1987]. This is a useful approach because the availability of high-quality phase equilibria data on this sytem allows the properties of a hypothetical pure olivine mantle to be readily calculated. The amount of olivine is the most critical difference between competing petrological models and can be determined from transition zone gradients and the parameters of the 400-km discontinuity as well as from absolute velocities. Furthermore, this approach allows us to make use of our new systematics and compare the results to other studies which have used different estimates and methods. In this way, we hope to identify those parameters which are most critical in distinguishing petrological models.

\section{Elasticity Data Set}

The measured or estimated elastic properties for a set of mantle minerals are compiled in Table 1. The experimental data consist largely of single-crystal ultrasonic, Brillouin, or resonance (RPR) measurements. Bulk properties are obtained from single-crystal values by the Voigt-ReussHill (VRH) averaging procedure [Watt et al., 1976]. The number in parentheses following each experimental value represents the uncertainty in the last digit. When several experimental values are combined to yield a single composite value, the quoted number represents the range of individual measurements. Normally, different experiments on the same material are in general agreement, although they may fall outside the individual experimental uncertainties. In these cases, a composite value is obtained by arithmetic averaging. For properties varying with iron content, ideal solid solution is assumed. In cases for which multiple measurements are clearly incompatible, the measurements believed to be most reliable are used. Entries in italics represent those values estimated using elasticity systematics and are discussed in detail below. The uncertainty in these estimates is unknown but is thought to be about $20 \%$ and can vary depending on the quality of the analogue data available.

There are a few specific entries that warrant further comment. The bulk modulus of olivine (and $\beta$ - and $\gamma$ spinel) is taken to be independent of Fe content. This is in conflict with the results of Sumino [1979] but in agreement with Graham et al. [1982] and Schwab and Graham [1983].

The moduli of $\mathrm{Mg}$-rich majorite were chosen to be the same as pyrope as inferred from Weidner et al. [1987]. This bulk modulus is inconsistent with the static compression value of Jeanloz [1981]. It is in reasonable agreement with the static compression value of Yagi et al. [1987] if the pressure derivative of the isothermal bulk modulus $K_{T}{ }^{\prime}$ is taken to be small. A previous static compression study of pyrope has also yielded a low $K_{T}{ }^{\prime}$ [Sato et al., 1978]. This may reflect a systematic bias due to the use of powdered samples since a single-crystal study of pyrope gave a result in excellent agreement with ultrasonics [Levien et al., 1979]. Bass [1986] evaluated elasticity systematics for garnets and concluded that the best fit to garnet elasticity data is obtained from the relation:

$$
V_{\phi} \bar{M}_{o}^{1 / 2}=\text { const }
$$

where $V_{\phi}$ is the bulk sound speed and $\bar{M}_{o}$ is the mean atomic weight. For 29 germanate and silicate garnets the constant in the above relationship is $31.77 \pm$ $1.14 \mathrm{~km} \mathrm{~g}^{1 / 2} \mathrm{~s}^{-1}$. This yields a bulk modulus for the magnesium-rich end-member majorite of $177 \pm 13 \mathrm{GPa}$, in agreement with the results of Yagi et al. [1987] and Weidner et al. [1987]. This relationship was also used to predict the bulk moduli of $\mathrm{Ca}$ - and $\mathrm{Na}$-rich majorites. We use the term "majorite" to refer to all high-pressure pyrox- 
TABLE 1. Elastic Properties of Mantle Minerals

\begin{tabular}{|c|c|c|c|c|c|c|c|}
\hline $\begin{array}{l}\text { Formula } \\
\text { (Name) }\end{array}$ & $\begin{array}{l}\text { Density }{ }^{a} \\
\mathrm{~g} / \mathrm{cm}^{3}\end{array}$ & $\begin{array}{l}K_{S} \\
\mathrm{GPa}\end{array}$ & $\begin{array}{c}G \\
\mathrm{GPa}\end{array}$ & $K_{S}^{\prime}$ & $G^{\prime}$ & $\begin{array}{r}\dot{K}_{S} \\
\mathrm{GPa} / \mathrm{K}\end{array}$ & $\begin{array}{c}\dot{G} \\
\mathrm{GPa} / \mathrm{K}\end{array}$ \\
\hline $\begin{array}{l}(\mathrm{Mg}, \mathrm{Fe})_{2} \mathrm{SiO}_{4} \\
\text { (olivine) }\end{array}$ & $\begin{array}{l}3.222(2)+ \\
1.182 \mathrm{X}_{\mathrm{Fe}}\end{array}$ & $129(2)^{b}$ & $\begin{array}{l}82(1)- \\
31(1) \mathrm{X}_{\mathrm{Fe}}^{b}\end{array}$ & $5.1(3)^{c}$ & $1.8(1)^{c}$ & $0.016(1)^{d}$ & $0.013(1)^{e}$ \\
\hline $\begin{array}{c}(\mathrm{Mg}, \mathrm{Fe})_{2} \mathrm{SiO}_{4} \\
(\beta \text {-spinel })\end{array}$ & $\begin{array}{l}3.472(5)+ \\
1.24(9) \mathrm{X}_{\mathrm{Fe}}\end{array}$ & $174(1)^{f}$ & $\begin{array}{l}114(1)- \\
41 \mathrm{X}_{\mathrm{Fe}}^{g}\end{array}$ & 4.9 & 1.8 & 0.018 & 0.011 \\
\hline $\begin{array}{c}(\mathrm{Mg}, \mathrm{Fe})_{2} \mathrm{SiO}_{4} \\
(\gamma \text {-spinel })\end{array}$ & $\begin{array}{l}3.548(1)+ \\
1.30 \mathrm{X}_{\mathrm{Fe}}\end{array}$ & $184(1)^{h}$ & $\begin{array}{l}119(1)- \\
41 \mathrm{X}_{\mathrm{Fe}}^{h}\end{array}$ & 4.8 & 1.8 & 0.017 & 0.011 \\
\hline $\begin{array}{l}(\mathrm{Mg}, \mathrm{Fe}) \mathrm{SiO}_{3} \\
\text { (orthopyroxene) }\end{array}$ & $\begin{array}{c}3.204(5)+ \\
0.799(5) \mathrm{X}_{\mathrm{Fe}}\end{array}$ & $104(4)^{i}$ & $\begin{array}{l}77(1)- \\
24(1) \mathrm{X}_{\mathrm{Fe}}^{i}\end{array}$ & 5.0 & 2.0 & 0.012 & 0.011 \\
\hline $\begin{array}{r}\mathrm{Ca}(\mathrm{Mg}, \mathrm{Fe}) \mathrm{Si}_{2} \mathrm{O}_{6} \\
\text { (clinopyroxene) }\end{array}$ & $\begin{array}{l}3.277(5)^{j}+ \\
0.380(1) \mathrm{X}_{\mathrm{Fe}}\end{array}$ & $\begin{array}{c}113(1)+ \\
7 \mathbf{X}_{\mathrm{Fe}_{\mathrm{e}}}^{k}\end{array}$ & $\begin{array}{l}67(2)- \\
6 \mathrm{X}_{\mathrm{Fe}}^{k}\end{array}$ & $4.5(1.8)^{l}$ & 1.7 & 0.019 & 0.010 \\
\hline $\begin{array}{l}\mathrm{NaAlSi}_{2} \mathrm{O}_{6} \\
\text { (jadeite) }\end{array}$ & $3.32(2)^{j}$ & $143(2)^{m}$ & $84(2)^{m}$ & 4.5 & 1.7 & 0.016 & 0.019 \\
\hline $\begin{array}{l}(\mathrm{Mg}, \mathrm{Fe}) \mathrm{O} \\
\text { (magnesiowustite) }\end{array}$ & $\begin{array}{l}3.583(1)+ \\
2.28(1) \mathrm{X}_{\mathrm{Fe}}\end{array}$ & $\begin{array}{l}163(1)- \\
8(5) \mathrm{X}_{\mathrm{Fe}}^{n}\end{array}$ & $\begin{array}{l}131(1)- \\
77(5) \mathrm{X}_{\mathrm{Fe}}^{n}\end{array}$ & $4.2(3)^{k}$ & $2.5(1)^{k}$ & $0.016(3)^{k}$ & $0.024(4)^{k}$ \\
\hline $\begin{array}{l}\mathrm{Al}_{2} \mathrm{O}_{3} \\
\text { (corundum) }\end{array}$ & $3.988(2)^{j}$ & $251(3)^{k}$ & $162(2)^{k}$ & $4.3(1)^{k}$ & $1.8(1)^{k}$ & $0.014(3)^{k}$ & $0.019(1)^{k}$ \\
\hline $\begin{array}{l}\mathrm{SiO}_{2} \\
\text { (stishovite) }\end{array}$ & $4.289(3)$ & $316(4)^{k}$ & $220(3)^{k}$ & 4.0 & 1.8 & 0.027 & 0.018 \\
\hline $\begin{array}{l}(\mathrm{Mg}, \mathrm{Fe})_{3} \mathrm{Al}_{2} \mathrm{Si}_{3} \mathrm{O}_{12} \\
\text { (garnet) }\end{array}$ & $\begin{array}{c}23.562(2)+ \\
0.758(3) \mathrm{X}_{\mathrm{Fe}}\end{array}$ & $\begin{array}{l}\text { 175(1) }+ \\
1(1) \mathrm{X}_{\mathrm{Fe}}^{k}\end{array}$ & $\begin{array}{l}90(1)+ \\
8(1) \mathrm{X}_{\mathrm{Fe}}^{k}\end{array}$ & $4.9(5)^{k}$ & $1.4(1)^{k}$ & $0.021(2)^{k}$ & $0.010(1)^{k}$ \\
\hline $\mathrm{Ca}_{3}(\mathrm{Al}, \mathrm{Fe})_{2} \mathrm{Si}_{3} \mathrm{O}_{12}$ & $3.595(2)+$ & $169(2)-$ & $104(1)-$ & 4.9 & 1.6 & $0.016^{p}$ & $0.015^{p}$ \\
\hline $\begin{array}{l}\text { (garnet) } \\
(\mathrm{Mg}, \mathrm{Fe}) \mathrm{SiO}_{3} \\
\text { (ilmenite) }\end{array}$ & $\begin{array}{c}0.265(1) \mathrm{X}_{\mathrm{Fe}}^{j} \\
3.810(4)+ \\
1.10(5) \mathrm{X}_{\mathrm{Fe}}\end{array}$ & $\begin{array}{l}11(2) \mathrm{X}_{\mathrm{Fe}}^{o} \\
212(4)^{q}\end{array}$ & $\begin{array}{c}14(1) \mathrm{X}_{\mathrm{Fe}}^{o} \\
132(9)- \\
41 \mathrm{X}^{g}\end{array}$ & 4.9 & 1.7 & 0.017 & 0.017 \\
\hline $\begin{array}{r}(\mathrm{Mg}, \mathrm{Fe}) \mathrm{SiO}_{3} \\
\text { (perovskite) }\end{array}$ & $\begin{array}{c}4.104(7)+ \\
1.07(6) \mathrm{X}_{\mathrm{Fe}}\end{array}$ & $266(6)^{r}$ & $159^{\mathrm{fe}}$ & $3.9(4)^{r}$ & 2.0 & 0.091 & 0.028 \\
\hline $\begin{array}{l}\mathrm{CaSiO}_{3} \\
\text { (perovskite) }\end{array}$ & $4.13(11)^{s}$ & 227 & 125 & 9.9 & 1.9 & 0.027 & 0.029 \\
\hline $\begin{array}{c}(\mathrm{Mg}, \mathrm{Fe})_{4} \mathrm{Si}_{4} \mathrm{O}_{12} \\
\text { (majorite) }\end{array}$ & $\begin{array}{c}3.518(3)+ \\
0.973(7) \mathrm{X}_{\mathrm{Fe}}\end{array}$ & $\begin{array}{l}175+ \\
1 X_{\mathrm{Fe}}^{t}\end{array}$ & $\begin{array}{l}90+ \\
8 \mathrm{X}_{\mathrm{Fe}}^{t}\end{array}$ & 4.9 & 1.4 & 0.021 & 0.010 \\
\hline $\begin{array}{c}\mathrm{Ca}_{2} \mathrm{Mg}_{2} \mathrm{Si}_{4} \mathrm{O}_{12} \\
\text { (majorite) }\end{array}$ & $3.59^{u}$ & 165 & 104 & 4.9 & 1.6 & 0.016 & 0.015 \\
\hline $\begin{array}{l}\mathrm{Na}_{2} \mathrm{Al}_{2} \mathrm{Si}_{4} \mathrm{O}_{12} \\
\text { (majorite) }\end{array}$ & $4.00^{\circ}$ & 200 & 127 & 4.9 & 1.6 & 0.016 & 0.015 \\
\hline
\end{tabular}

$K_{S}$, adiabatic bulk modulus; $G$, shear modulus; $K_{S}{ }^{\prime}$, pressure derivative of the adiabatic bulk modulus; $G^{\prime}$, pressure derivative of the shear modulus; $\dot{K}_{S}$, absolute value of the temperature derivative of the adiabatic bulk modulus; $\dot{G}$, absolute value of the temperature derivative of the shear modulus; $X_{F e}$, mole fraction of iron. The number in parentheses following each experimental value represents the uncertainty in the last digit. Entries in italics represent those values estimated using elasticity systematics.

a All densities from Jeanloz and Thompson [1983] except where indicated.

b Graham et al. [1982], Schwab and Graham [1983], Suzuki et al. [1983], Sumino and Anderson [1984], and Yeganeh-Haeri and Vaughan [1984].

c Schwab and Graham [1983] and Sumino and Anderson [1984].

d Suzuki et al. [1983] and Sumino and Anderson [1984].

e Schwab and Graham [1983], Suzuki et al [1983], and Sumino and Anderson [1984].

$f$ Sawamoto et al. [1984].

$g$ Sawamoto et al. [1984]. The effect of Fe on the modulus is from Weidner et al. [1984].

h Weidner et al. [1984].

i Sumino and Anderson [1984], Bass and Weidner [1984], and Duffy and Vaughan [1988].

j Robie et al. [1966].

$k$ Sumino and Anderson [1984].

Levien and Prewitt [1981].

$m$ Kandelin and Weidner $[1988 a, b]$.

$n$ Sumino and Anderson [1984]. The variation with Fe content is unclear. (See Graham and Kim [1986] for a review.)

- Halleck [1973] and Bass [1986]. Linear variation of moduli between end members is assumed [Haniford and Weidner, 1985].

$p \quad$ Isaak and Anderson [1987].

$q$ Weidner and Ito [1985]. The variation with iron content is modeled by analogy with orthopyroxene

r Knittle and Jeanloz [1987].

- Base [1984].

$t$ Inferred from Weidner et al. [1987].

4 Akaogi et al. [1987].

v Estimated by Bass and Anderson [1984]. 
ene phases that crystallize in the garnet structure. There is a large uncertainty in the densities of the Na-rich majorites, and the computed seismic velocities are therefore uncertain.

Shear modulus systematics are less well established than bulk modulus systematics. Silicate and germanate garnet elasticity data indicate that the product, $V_{p} \bar{M}_{o}^{1 / 2}$, where $V_{p}$ is the compressional sound speed, is also relatively constant. The standard deviation for this relation is a factor of 2 greater than for the previous relation. This yields a shear modulus for $\mathrm{Mg}$-rich majorite of $99 \pm 28$ $\mathrm{GPa}$, in reasonable agreement with the result of Weidner et al. [1987]. For Ca-majorite the estimated value is $91 \pm$ $25 \mathrm{GPa}$. If only data from $\mathrm{Ca}$-rich garnets are considered, then the preferred value is $105 \mathrm{GPa}$. For Na-majorite the estimated value is $109 \pm 32 \mathrm{GPa}$. The uncertainties in estimated shear moduli values are about a factor of 2 larger than bulk moduli uncertainties.

A second technique for estimating the shear modulus utilizes the observation that garnet shear modulus data show relatively little variability. A useful way to further reduce variability is to normalize the ratio $K_{S} / G$ by the $K_{S} / G$ ratio of the constituent oxides, giving $\left(K_{S} / G\right)_{n}$ [Anderson, 1986]. The coordination of the oxides must be taken into account in this method which necessitates the derivation of a set of fictive $K_{S} / G$ ratios from the existing elasticity database. For garnets this procedure reduces the variability in $K_{S} / G$ from $25 \%$ to $15 \%$ and yields the result

$$
\left(\frac{K_{S}}{G}\right)_{n} \approx 1.06
$$

The estimated shear modulus of $\mathrm{Mg}$-majorite by this procedure is $104 \mathrm{GPa}$, in good agreement with Weidner et al. [1987]. The shear moduli of $\mathrm{Ca}$ - and $\mathrm{Na}$-majorite shown in Table 1 were estimated in this way.

Pyroxene elasticity data also merit some comment. Aluminous orthopyroxenes, except jadeite, are not considered due to lack of relevant data. The pressure and temperature derivatives of orthopyroxene are estimated, despite the fact that experimental values exist [Frisillo and Barsch, 1972]. The measured values are highly anomalous, however, and large negative second derivatives are expected to rapidly reduce them to more normal values such as used here [Webb and Jackson, 1985].

The bulk modulus of $\mathrm{Mg}$-rich perovskite is taken from Knittle and Jeanloz [1987] without making the correction from isothermal to adiabatic conditions. For $\mathrm{Ca}$-perovskite the same bulk modulus results from either of the relations: $K V_{m}=$ const or $V_{\phi} \bar{M}_{o}^{1 / 2}=$ const, where $K$ is the bulk modulus and $V_{m}$ is the molar volume [Bass, 1984]. The shear modulus values of Table 1 for perovskites were obtained using the relation, $V_{p} \bar{M}_{o}^{1 / 2}=$ const. This relation holds remarkably well over a wide range of perovskite compositions [Bass, 1984]. The standard deviation of $V_{p} \bar{M}_{o}^{1 / 2}=$ const is only $10 \%$ higher than for $V_{\phi} \bar{M}_{o}^{1 / 2}=$ const. Thus we feel that realistic shear moduli for this structure are obtainable using this relation.

Substitution of $\mathrm{Fe}$ for $\mathrm{Mg}$ increases the $K_{s} / G$ ratio for many structures [Weidner et al., 1982] and is also expected to decrease $d G / d P$ (see Figure 2). The magnitude of this effect is small compared to other certainties for $\mathrm{Fe}$ fractions of less than 0.15 such as are considered here. In a few cases, where static compression results have been used to estimate the pressure derivative of the isothermal bulk modulus $K_{T}{ }^{\prime}$ no correction has been made between isothermal and adiabatic conditions, a small correction compared to experimental uncertainties.

\section{Derivatives}

In the previous section, existing data were used to obtain a compilation of measured and estimated elastic properties for mantle minerals. However, for a large number of materials, pressure and temperature derivatives of elastic moduli have not been measured. In this section, we obtain estimates for these quantities.

The search for relationships is based on the large existing elasticity data base which consists primarily of the compilation of Sumino and Anderson [1984], supplemented by more recent studies. The data set used here consists of 329 measurements on 149 minerals for which 10 crystal structures are represented by five or more specimens. The breadth of this compilation is an important advantage since it allows potential relationships to be tested over a range of chemistry and structure. By treating a large, diverse data set it is possible to see trends with ionic radius, $K_{S} / G$, and $\gamma$ [Anderson, 1988]. These trends are often not evident if attention is limited to "geophysically relevant" compounds (silicates) because of the small range and small number of measured samples and the low precision of data on relatively incompressible compounds [Davies, 1976].

Systematics among derivatives of elastic properties have proven to be rather elusive [e.g., Davies, 1976] particularly for the oxides and silicates. The bulk modulus pressure derivative $\left(d K / d P\right.$ or $\left.K^{\prime}\right)$ is particularly resistant to description by convincing systematics. However, this parameter exhibits little total variation, and uncertainties in its variation from material to material are relatively unimportant for discussions of the upper mantle. On the other hand, the temperature and pressure derivatives of the rigidity display a large variability, and it is the choice of these parameters that has led to most of the conflicting conclusions about the composition of the transition region. Anderson [1988] isolated ionic radius as a controlling variable in shear modulus derivatives: halides, oxides, and silicates follow the same trends. Again, the total range of ionic radii in measured silicates is much smaller than in the data set considered, and variations with this parameter could be overlooked.

The limitations of the database must be born in mind. While we primarily utilize high-quality single-crystal data, a variety of experimental techniques have been used. For derivatives there is a great deal of variation in the pressure and temperature range of the experiments. The net result is that different experiments conducted on the same material can produce widely differing results. As a particularly egregious example, the eight reported bulk modulus pressure derivatives for $\mathrm{NaCl}$ range from 3.72 to 5.91 . No attempt has been made to critically evaluate each experiment. Where multiple measurements of a single quantity exist, the results have simply been arithmetically averaged. It should be pointed out that the results obtained in this way are not significantly different from those obtained by Anderson [1988], who selected a single measured value for each material. 
Bulk modulus pressure derivatives exhibit the least total variability and the greatest experimental scatter. Previous estimation schemes have been limited in scope and have not proven generally useful [Chung, 1973; Anderson, 1973|. On the other hand, since $K_{S}$ ' does not vary much, its magnitude is fairly easy to estimate.

Theoretical considerations indicate that $K_{T}{ }^{\prime}$ depends only on the repulsive range parameter in a central force model of the interatomic potential [Anderson and Anderson, 1970]. Thus $K_{T}$ ' should be a linear function of interatomic spacing. Analysis of the elasticity data set provides general empirical support for this result. The relationship holds best for ionic diatomic materials for which interatomic spacing can be reliably estimated and crystal structure effects are less important. Data also show that $K_{S}{ }^{\prime}$ increases as the Grüneisen parameter increases, although not in the manner predicted by the Slater formula.

A third relation involving the pressure derivative is that $K_{S}$ ' decreases with the product $K_{S} r$, where $r$ is a measure of interatomic spacing. The quantity $\left(\bar{M}_{o} / \rho\right)^{1 / 3}$, where $\rho$ is the density, can be taken as a measure of interatomic spacing. In Figure 1, structural averages of $K_{S}{ }^{\prime}$ have been plotted against average values of $K_{S}\left(\bar{M}_{o} / \rho\right)^{1 / 3}$ for available data. The bars indicate the range for each structure. Highly anomalous values are plotted separately (e.g., $\mathrm{MgO}$ ). By plotting structural averages, it is hoped that some of the uncertainty in individual measurements will average out. Experimental uncertainties are particularly large for the relatively incompressible silicates and oxides. According to Figure $1, K_{S}{ }^{\prime}$ is a linear function of $K_{S}\left(\bar{M}_{o} / \rho\right)^{1 / 3}$. Since $K_{S}\left(\bar{M}_{o} / \rho\right)^{1 / 3}$ tends to be constant for each structure, this relation clearly delineates the role of crystal structure and chemistry in determining $K_{S}{ }^{\prime}$. Some structures violate the indicated trend such as rutiles, a structure well known to exhibit unusual elastic behavior, and Cs-chlorides (not shown in Figure 1) many of which contain "exotic" ions such as Cs or Tl. Properties of these

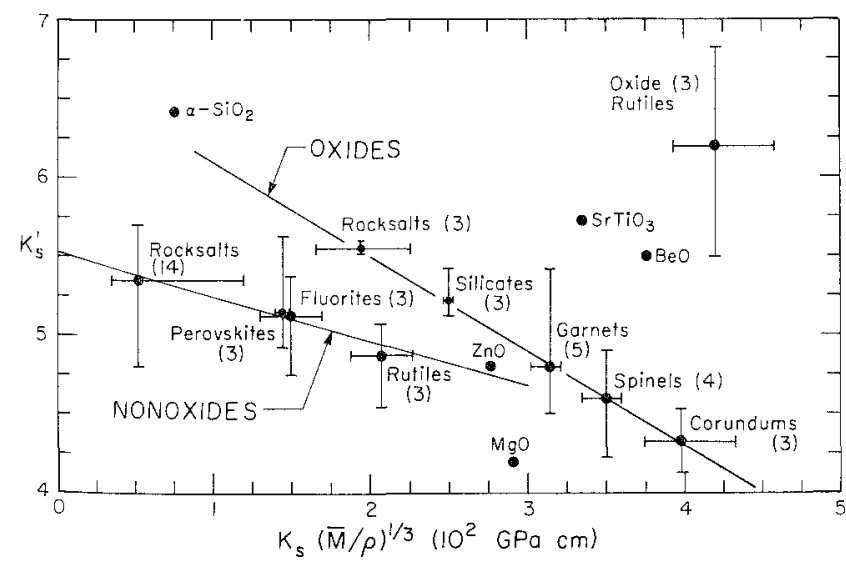

Fig. 1. Pressure derivative of the bulk modulus plotted against the product of the bulk modulus and average interatomic spacing. The cube root of the mean atomic weight divided by density is taken as a measure of average spacing. Circles represent average values for each structure, while the error bars represent the range of measured values. Materials which are unusually anomalous or belong to structures which contain two or fewer samples are plotted separately. The number in parentheses following each structure label is the number of samples averaged together for that structure. cations may explain the large values of $K_{S}{ }^{\prime}$ often found in this structure.

The procedure for obtaining the estimates of $K_{S}{ }^{\prime}$ in Table 1 depended on the type of existing data that could be applied to a given mineral. For some materials, static compression studies provide the only available estimates of $K_{T}{ }^{\prime}$. However, error bars on these kinds of measurements are quite large. Therefore we examined the predictions of the three methods discussed above and adjusted the measured value, within its error bars, until consistency with all available information is attained. In most cases, the required adjustments are small or zero.

For the remaining unmeasured materials there are usually derivative data for some analogue compound. In these cases we take the analogue value and adjust it in accordance with the trends noted above. Again, with a few exceptions the adjustments are very small, of the order of 0.1-0.3. It becomes important in this scheme to identify the proper analogue for a given material. For example, $\mathrm{Al}_{2} \mathrm{O}_{3}$ is held to be a good analogue for $\mathrm{MgSiO}_{3}$ ilmenite in that the ions ${ }^{\mathrm{VI}} \mathrm{Mg}$ and ${ }^{\mathrm{VI}} \mathrm{Si}$ can readily substitute for ${ }^{V I} \mathrm{Al}_{2}$ and they have similar ionic radii and bulk moduli.

Another important case is that of the silicate spinels, where olivine (same chemistry, different structure) rather than aluminate spinel (different chemistry, similar structure) is taken as the best analogue for $\beta$ - and $\gamma$-spinel. The basis for this is that $\mathrm{Mg}-\mathrm{O}$ and $\mathrm{Si}-\mathrm{O}$ coordinations and interatomic distances are the same or similar in $\alpha, \beta$, and $\gamma$. The ions, charges, and ionic distances are dissimilar in silicate and aluminate spinels [Anderson, 1988]. Furthermore, $\alpha, \beta$, and $\gamma$ have similar $K_{S} / G$ ratios and elastic anisotropies, while silicate and aluminate spinels do not. These quantities are important indicators of elastic character [Weidner and Hamaya, 1983; Bass et al., 1984].

The static compression result of Sawamoto et al. [1987] suggests that $K_{T}{ }^{\prime}$ for silicate spinels may be somewhat less than for olivine, although the errors are too large to say this with certainty. This is consistent with our systematics which suggests that $K_{S}{ }^{\prime}$ for the spinels should be only slightly less than for olivine. The experimental results of Fujis awa [1987] imply that the pressure derivatives of both $K_{S}$ and $G$ do not differ much between $\alpha$-olivine and $\beta$-spinel. Finally, static compression results also indicate that $K_{T}{ }^{\prime}$ for $\gamma$-spinel is the same as or slightly less than $K_{T}{ }^{\prime}$ for olivine [Jeanloz and Thompson, 1983]. Our estimates for $\beta$ and $\gamma$ are similar to those of Anderson [1988] and Bina and Wood [1987] (see Table 3). However, the values of Irifune [1987] and Weidner [1986] are considerably lower. They fall below the trend lines in Figure 1, close to the value for $\mathrm{MgO}$. No measured silicate has such low values.

Relationships involving the pressure derivative of the shear modulus are, surprisingly, less ambiguous. Theoretical considerations suggest that the pressure derivative of the shear modulus $G^{\prime}$ should depend on coordination and Poisson's ratio [Anderson, 1968; Davies, 1976]. Anderson [1988] pointed out additional relationships involving the dimensionless logarithmic anharmonic (DLA) parameter, $\{G\}_{T}$, which is given by

$$
\{G\}_{T}=\left(\frac{\partial \ln G}{\partial \ln \rho}\right)_{T}=\frac{K_{T}}{G}\left(\frac{\partial G}{\partial P}\right)_{T}
$$




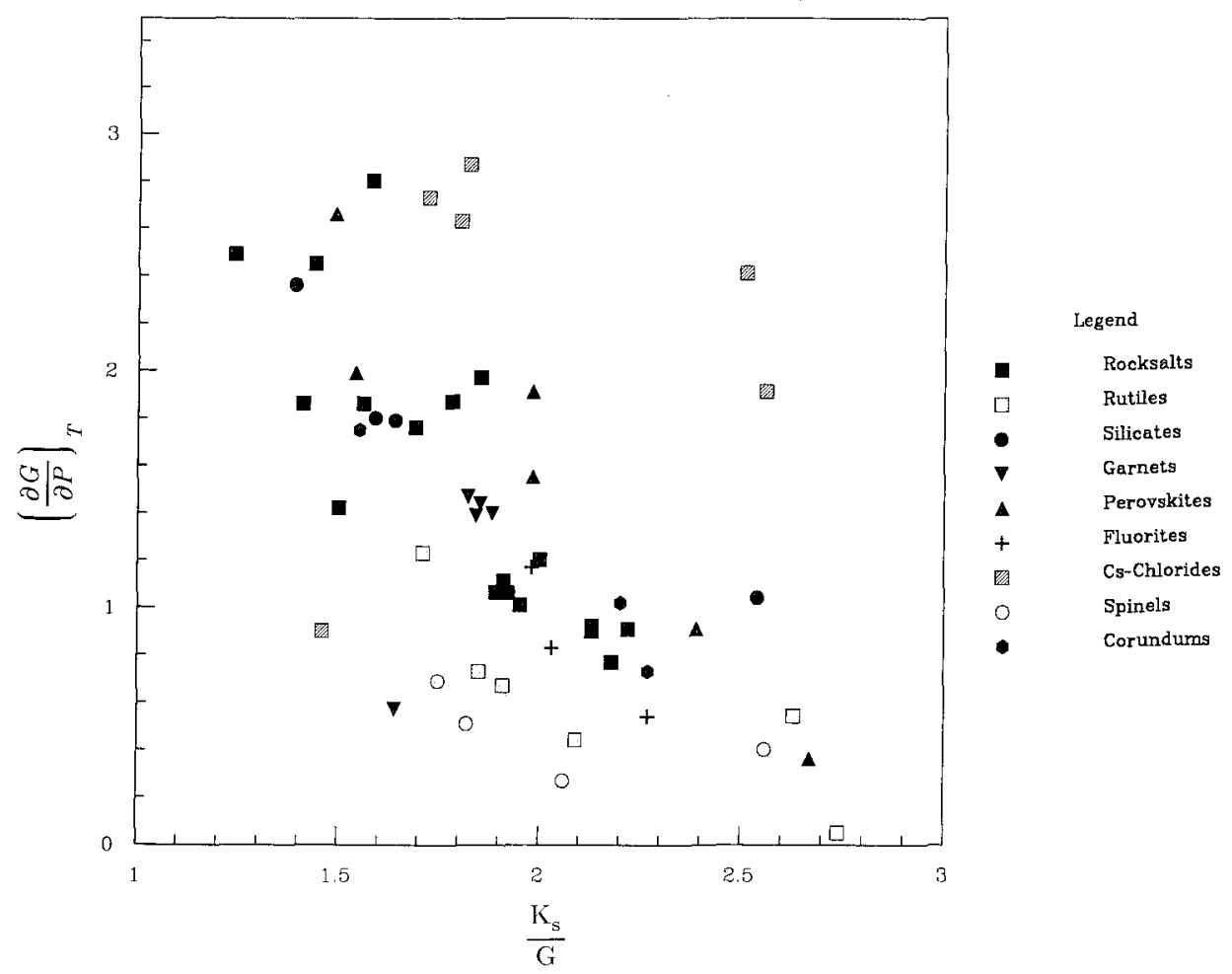

Fig. 2. Pressure derivative of the rigidity plotted against the ratio of bulk to shear modulus. Variation of $G^{\prime}$ with the ratio $K_{S} / G$ is evident for each of the structures represented, although there are a few anomalous points.

$\{G\}_{T}$ is found to decrease with $K_{S} / G$, which is related to Poisson's ratio, and with cation and anion radius. In Figure 2, $G^{\prime}$ is plotted against the ratio $K_{S} / G$ for available data. For a given structure, $G^{\prime}$ varies as a function of $K_{S} / G$, allowing the estimates of Table 1 to be constructed. Our results for the spinel phases are similar to the estimates of Anderson [1988] and Bina and Wood [1987] and are comparable to olivine. The values adopted by Irifune [1987] and Weidner [1986] are approximately one-half the value for olivine and occupy an extremum position on Figure 2.

There are a number of trends evident in the data set involving the temperature derivatives, $\left|\left(\partial K_{S} / \partial T\right)_{P}\right|=$ $\dot{K_{S}}$ and $\left|(\partial G / \partial T)_{P}\right|=\dot{G}$. Both $\dot{K_{S}}$ and $\dot{G}$ decrease as molar volume increases. Again, the trend is particularly evident for simpler structures. $\dot{K}_{S}$ tends to increase with the product $\alpha K_{S}$, where $\alpha$ is the volume coefficient of thermal expansion. Furthermore, both $\dot{K_{S}}$ and $\dot{G}$ increase with the acoustic Debye temperature, $\theta_{D}$, until $\theta_{D} \approx 800 \mathrm{~K}$ at which point they level off. The data set also shows that logarithmic temperature derivatives $(\partial \ln M / \partial T)_{P}$ are not approximately constant as claimed by Bina and Wood [1987]. While the above trends all give some idea of how temperature derivatives behave, a more rigorous procedure for estimating them can be obtained.

The temperature effect can be separated into intrinsic and extrinsic components [Jones, 1976]:

$$
\left(\frac{\partial M}{\partial T}\right)_{P}=\left(\frac{\partial M}{\partial T}\right)_{V}-\alpha K_{T}\left(\frac{\partial M}{\partial P}\right)_{T}
$$

where $M$ is an elastic modulus and $\alpha$ is the coefficient of volume expansion. The same result can be represented in dimensionless form [Anderson, 1988]:

$$
\frac{1}{\alpha M}\left(\frac{\partial M}{\partial T}\right)_{P}=\frac{1}{\alpha M}\left(\frac{\partial M}{\partial T}\right)_{V}-\frac{K_{T}}{M}\left(\frac{\partial M}{\partial P}\right)_{T}
$$

Or, in terms of DLA parameter notation,

$$
\{M\}_{P}=\{M\}_{V}-\{M\}_{T}
$$

where the terms in braces are defined as

$$
\begin{gathered}
\{M\}_{P} \equiv\left(\frac{\partial \ln M}{\partial \ln \rho}\right)_{P}=\frac{1}{\alpha}\left(\frac{\partial \ln M}{\partial T}\right)_{P} \\
\{M\}_{V} \equiv \frac{1}{\alpha}\left(\frac{\partial \ln M}{\partial T}\right)_{V} \\
\{M\}_{T} \equiv\left(\frac{\partial \ln M}{\partial \ln \rho}\right)_{T}=K_{T}\left(\frac{\partial \ln M}{\partial P}\right)_{T}
\end{gathered}
$$

The extrinsic term $\{M\}_{T}$, can be computed from known or previously estimated quantities (equation (7)). The intrinsic term $\{M\}_{V}$ is assumed to be constant for a given crystal structure and is computed from existing data. 


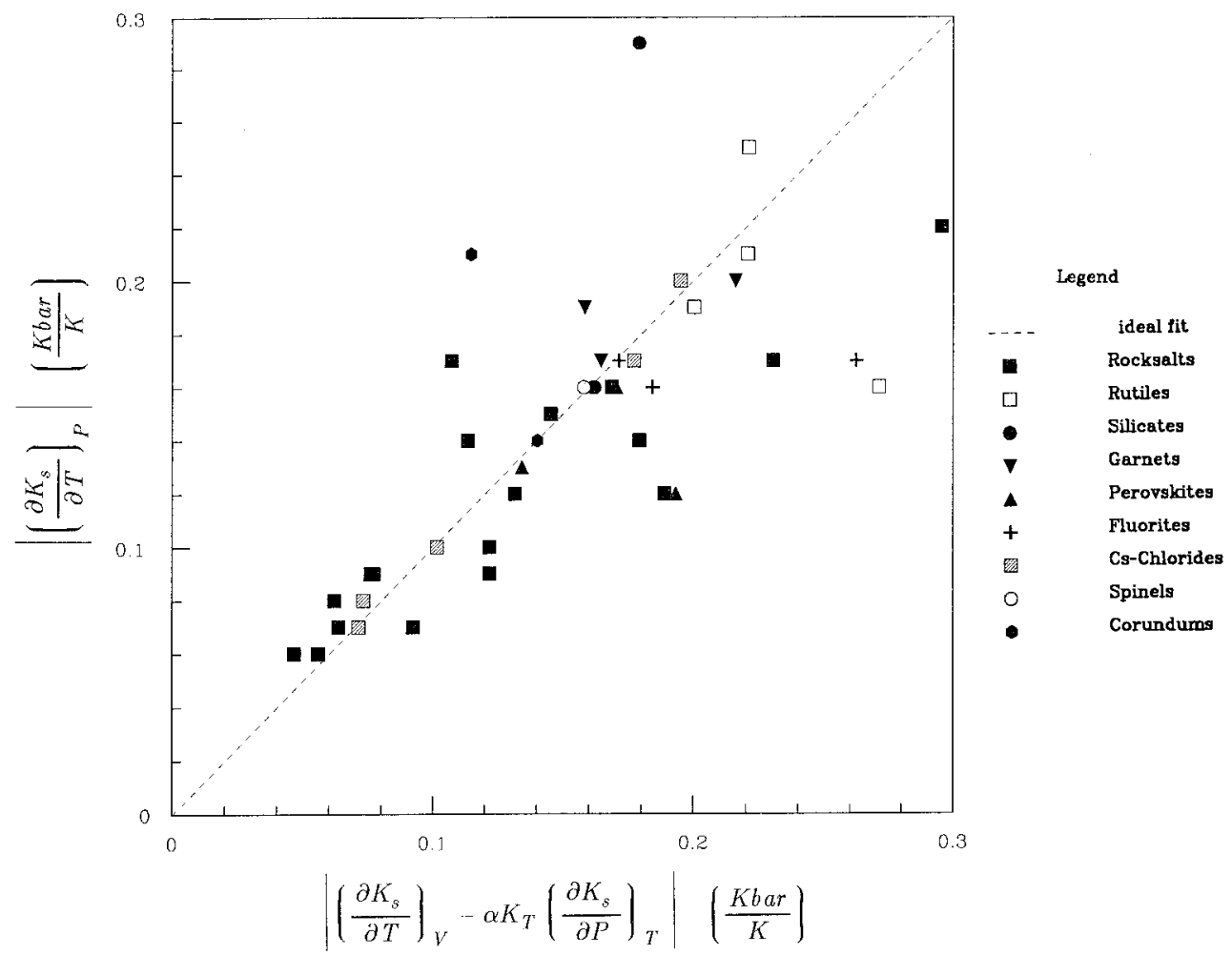

Fig. 3. Measured bulk modulus temperature derivatives versus predicted temperature derivatives, based on the decomposition discussed in the text. The extrinsic term is calculated from the modulus, its pressure derivative, and the coefficient of volume expansion. The intrinsic term is derived empirically from structure averages. For some structures (e.g., silicates) the correction term is zero.

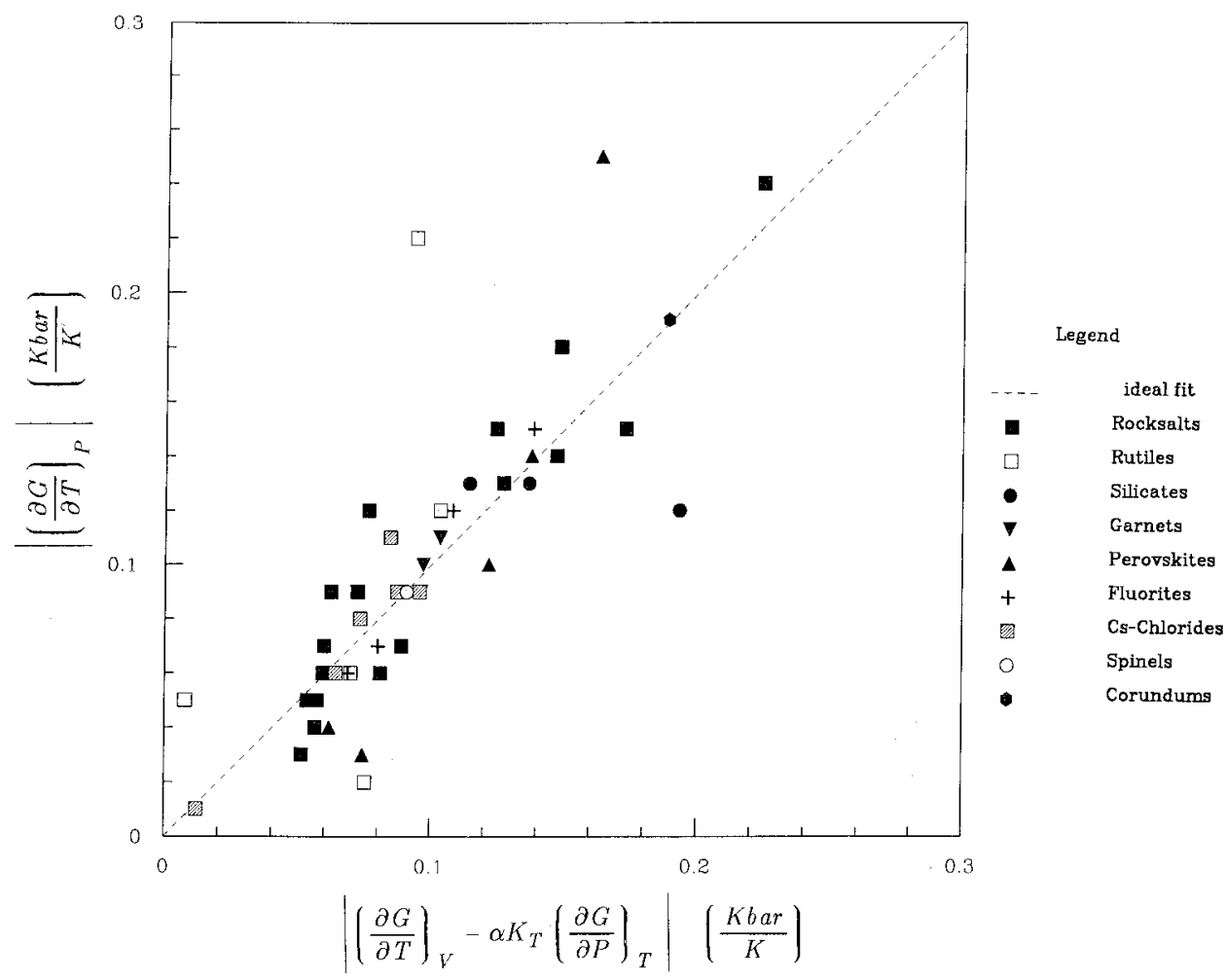

Fig. 4. Same as Figure 3 except in this case for the rigidity. The scatter is somewhat lower for the rigidity systematics than for the bulk modulus systematics. However, the magnitude of the intrinsic term is generally larger for the shear modulus. 
In Figures 3 and 4, existing data are compared to Equation (2). In general, there is good agreement between measured temperature derivatives and those predicted, although the scatter is somewhat greater for $\dot{K}_{S}$. In practice, there is relatively little difference between the predictions of equations (2) and (3).

Initial estimates of all derivatives were obtained using the above schemes. The estimates were then examined for internal consistency and for agreement with known trends. If necessary, values were then perturbed to give better overall agreement with the systematics. The result is a set of self-consistent estimates based on the trends uncovered in our analysis of the elasticity data set. These estimates are also objective, in that they are derived with no particular petrological model for the mantle in mind.

Note that the pressure and temperature derivatives of the $\beta$ and $\gamma$ phases adopted in this study are similar to those of olivine. This is expected because the chemistries are identical, the coordinations are the same, and the cation-anion distances are similar. When a large data set is considered, there are correlations of the derivatives with $K_{S} / G$, ionic radii, and Grüneisen's $\gamma$ [Anderson, 1988]. These parameters are also similar for the various phases of olivine and there is therefore no reason to expect the derivatives of $\beta$ and $\gamma$ to differ much from olivine. We see little justification for adopting high $T$ derivatives [e.g., Bina and Wood, 1987] or low P-derivatives [Weidner, 1986; Irifune, 1987] or high ratios of the $T$ derivatives to $P$ derivatives for the spinel forms of olivine.

\section{Velocities as a Function of Temperature AND PRessure}

With the information available in Table 1 , seismic velocities can be computed in these minerals as a function of temperature and pressure. The procedure is first to correct for the effect of temperature by calculating the properties at the foot of an appropriate adiabat. The properties are then extrapolated adiabatically to depth using finite strain theory.

The first step in this process is the calculation of hightemperature densities using volume expansion data. Expansion coefficients are temperature dependent and must be extrapolated beyond the upper limit of the experimental data (generally $700^{\circ}-1000^{\circ} \mathrm{C}$ ). This was accomplished using Grüneisen theory, an approximate statistical mechanical model for the thermal expansion of a solid. To second order in strain, Grüneisen theory predicts that volume is given by [Suzuki et al., 1979b]:

$$
V(T)=\frac{V\left(T_{o}\right)}{2 k a_{v}}\left(1+2 k-\sqrt{1-\frac{4 k E\left(\theta_{D}, T\right)}{Q_{o}}}\right)
$$

where $V(T)$ is the volume at a given temperature $T, V\left(T_{o}\right)$ is the volume at some reference temperature $T_{o}, k$ is an anharmonic parameter, $\theta_{D}$ is the Debye temperature, $E$ is the internal energy, $Q_{o}$ is the ratio of heat capacity to the thermal expansion at $0 \mathrm{~K}[$ Suzuki, $1975 a]$, and $a_{v}$ is a correction term which accounts for the reference temperature being different from absolute zero.

Volume-temperature data were fit to equation (8), or when available, previously published fits were used. The general procedure is to compute the internal energy from the Debye temperature and the Nernst-Lindemann energy function. The parameter $k$ is estimated from the pressure derivative of the bulk modulus. $Q_{o}$ and $a_{v}$ are found by an iterative least squares technique; hence their values are not necessarily physically meaningful. The parameters used in equation (8) for the minerals of this study are shown in Table 2. Thermal expansion coefficients as a function of temperature are than obtained by differentiation of volumetemperature data (Figure 5).

High temperature densities are computed from

$$
\rho(T)=\rho\left(T_{o}\right) e^{-\int_{T_{o}}^{T} \alpha\left(T^{\prime}\right) d T^{\prime}}
$$

where $\rho(T)$ and $\rho\left(T_{o}\right)$ are the high-temperature and reference temperature densities, respectively. The primary uncertainty in this calculation is the form of the expansion curve (Figure 5) due to the uncertainties involved in extrapolation. Nevertheless, high-temperature densities are believed to be accurate to $1 \%$ or better.

TABLE 2. Thermal Expansion Parameters

\begin{tabular}{lllllll}
\hline & $\begin{array}{c}Q_{o}, \\
10^{6} \mathrm{~J} / \mathrm{mol}\end{array}$ & $k$ & $\begin{array}{c}a_{v}, \\
\mathrm{X10}^{-2}\end{array}$ & $\begin{array}{c}\theta_{D}, \\
\mathrm{~K}\end{array}$ & $\begin{array}{c}\alpha(298 \mathrm{~K}), \\
10^{-6} \mathrm{~K}^{-1}\end{array}$ & Reference \\
\hline & & & & & & \\
$\alpha$-olivine & $\mathbf{5 . 0 4 4}$ & 2.05 & 1.00390 & 732 & 26.8 & $\mathrm{a}$ \\
$\beta$-spinel & $\mathbf{5 . 3 2}$ & 2.0 & 1.00188 & 952 & 21.5 & $\mathrm{~b}$ \\
$\gamma$-spinel & 6.42 & 2.0 & 1.00256 & 849 & 19.3 & $\mathrm{c}$ \\
Enstatite & $\mathbf{3 . 6 8}$ & 1.75 & 1.00402 & 738 & 26.0 & $\mathrm{~d}$ \\
Diopside & $\mathbf{3 . 9 3}$ & 1.75 & 1.00332 & 673 & 25.5 & $\mathrm{e}$ \\
Periclase & 1.14 & 1.60 & 1.00347 & 942 & 28.9 & $\mathrm{a}$ \\
Corundum & 4.61 & 1.65 & 1.00151 & 1031 & 16.6 & $\mathrm{f}$ \\
Pyrope & 16.5 & 1.50 & 1.00337 & 698 & 23.8 & $\mathrm{~g}$ \\
Stishovite & $\mathbf{3 . 0 3}$ & 1.50 & 1.00107 & 1192 & 13.2 & $\mathrm{~h}$ \\
Perovskite & $\mathbf{2 . 8 8}$ & 1.50 & 1.0 & 825 & 31.4 & $\mathrm{i}$ \\
\hline
\end{tabular}

References: a, Suzuki [1975a]; b, Suzuki et al. [1980]; c, Suzuki et al. [1979a]; d, Suzuki [1975b]; e, Deganello [1973]; Cameron et al. [1973]; Finger and Ohashi [1976]; $f$, Wachtman et al. [1962]; g, Suzuki and Anderson [1983]; h, Ito et al. [1974]; i, Knittle et al. [1986]. 


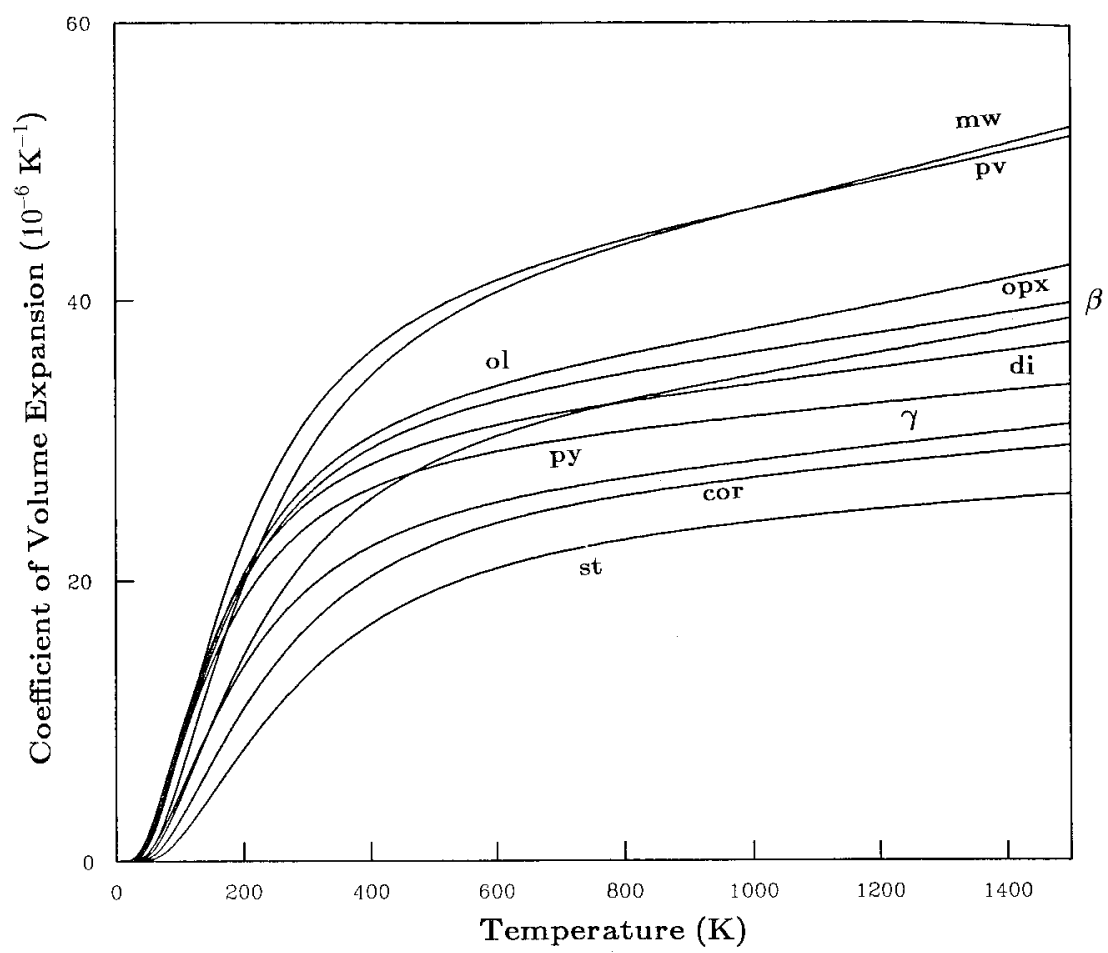

Fig. 5. Thermal expansion data fit to a Grüneisen function for available data on mantle minerals. The expansion coefficient increases rapidly at moderate temperatures but becomes nearly constant at temperatures at or near the Debye temperature. The abbreviations are $\mathrm{mw}$, magnesiowüstite; $\mathrm{pv}$, perovskite; ol, olivine; opx, orthopyroxene; $\beta$, beta-spinel; di, diopside; $\gamma$, gamma-spinel; cor, corundum; st, stishovite.

Elastic moduli at high temperature can be obtained in a number of ways. A common scheme is to perform a Taylor expansion about a reference temperature as follows:

$$
\begin{gathered}
M(T) \approx M\left(T_{o}\right)+\left(\frac{\partial M}{\partial T}\right)_{P}\left(T-T_{o}\right) \\
+\frac{1}{2}\left(\frac{\partial^{2} M}{\partial T^{2}}\right)_{P}\left(T-T_{o}\right)^{2}+\ldots
\end{gathered}
$$

Most existing high-temperature elasticity data only extend to $500^{\circ} \mathrm{C}$, although a few studies have achieved $1000^{\circ} \mathrm{C}$. From this limited data, higher-order terms cannot usually be reliably obtained (see Suzuki et al. [1983] and Sumino et al. [1983] for exceptions), and the expansion is normally truncated at terms linear in temperature [Bina and Wood, 1987; Weidner, 1986]. Other calculation methods assume the constancy of some thermodynamic parameter such as $\gamma$ or $\delta_{S}$ or involve curve fitting to some predetermined functional form le.g., Suzuki et al., 1983; Sumino et al., 1983].

The high-temperature moduli used here were obtained by consideration of the DLA parameter under isobaric conditions (equation (5)). If this parameter is assumed to be constant with temperature, integration yields the following temperature equation of state [Anderson, 1988]:

$$
M(T)=M\left(T_{o}\right)\left(\frac{\rho(T)}{\rho\left(T_{o}\right)}\right)^{\{M\}_{P}}
$$

Since the DLA parameters have been shown to vary slightly with chemistry but very little with structure, it is reasonable to suppose that they will not vary with temperature. Existing experimental data, where available, do not contradict this contention. The assumption, $\{M\}_{P}$ constant, is identical to assuming $\delta_{S}=$ const when $M$ $=K_{S}$.

Comparison of equations (10) and (11) to existing experimental data indicates that both predict moduli within experimental uncertainty and differ by $2 \%$ or less. In view of the experimental uncertainties and those introduced by Voigt-Reuss-Hill averaging of the moduli, the form of the temperature equation is likely to be a small contributor to the overall uncertainty. In general, equation (11) produces moduli which are lower than those given by equation (10). The difference increases with temperature, and for the temperature range considered here (up to $2000^{\circ} \mathrm{C}$ ) the difference in the resulting velocities is usually $6 \%$ or less. However, ratios of velocities between phases change by less than $2 \%$. Thus the effect of the temperature equation of state will be largely reflected in the temperature used to initiate the adiabat and only to a lesser degree in the resulting mineral compositions.

According to the scheme that we have adopted, $\left|\left(\partial K_{S} / \partial T\right)_{P}\right|$ increases with temperature. In order for $\{M\}_{V}$ to remain constant with temperature, $(\partial M / \partial P)_{T}$ must also increase with temperature. This is consistent with both theoretical considerations (Wolf and Bukowin$s k i, 1987]$ and limited experimental data for $\mathrm{MgO}$ and $\mathrm{NaCl}$ on simultaneous application of pressure and temperatures [Spetzler, 1969; Spetzler et al., 1972]. The magnitude of the effect is difficult to quantify. If we use Earth model PREM [Dziewonski and Anderson, 1981] parameters for the lower mantle as a guide, we find that 


$$
\frac{\partial \ln M^{\prime}}{\partial \ln \rho} \approx-1
$$

where $M^{\prime}$ is the pressure derivative of a modulus. This is roughly consistent with the $\mathrm{NaCl}$ data, although shear data may imply a stronger dependence on density. Use of equations (9) and (12) yields the following relation for high-temperature pressure derivatives:

$$
M^{\prime}(T)=M^{\prime}\left(T_{o}\right) e^{\int_{T_{o}}^{T} \alpha\left(T^{\prime}\right) d T^{\prime}}
$$

High-temperature physical properties were then projected adiabatically into the mantle using third-order finite strain theory. The expressions for compressional and shear velocities can be cast into the form [Davies and Dziewonski, 1975]

$$
\begin{gathered}
\rho V_{P}^{2}=(1-2 \epsilon)^{5 / 2}\left(L_{1}+L_{2} \epsilon\right) \\
\rho V_{S}^{2}=(1-2 \epsilon)^{5 / 2}\left(M_{1}+M_{2} \epsilon\right) \\
P=-(1-2 \epsilon)^{5 / 2}\left(C_{1} \epsilon+C_{2} \epsilon^{2} / 2\right)
\end{gathered}
$$

where the strain $\epsilon$ is given by

$$
\epsilon=1 / 2\left[\left(1-\rho / \rho_{o}\right)^{2 / 3}\right]
$$

$\rho$ is the density, $\rho_{o}$ is the zero pressure density, $P$ is the pressure, and $V_{P}$ and $V_{S}$ are the compressional and shear velocities, respectively.

The coefficients are

$$
\begin{gathered}
M_{1}=G \\
L_{1}=K+(4 / 3) G \\
C_{1}=3 L_{1}-4 M_{1} \\
M_{2}=5 G-3 K G^{\prime} \\
L_{2}=5(K+(4 / 3) G)-3 K\left(K^{\prime}+(4 / 3) G^{\prime}\right) \\
C_{2}=3 L_{2}-4 M_{2}+7 C_{1}
\end{gathered}
$$

For a given pressure, equation (14c) was used to obtain the strain $\epsilon$. From (15), (14a), and (14b) the density and sound speeds are obtained. The parameters (16) are determined from Table 1, having made appropriate temperature corrections. Here again we differ with Weidner [1986], who assumed a linear dependence of $K_{S}$ and $G$ on $P$, which is not a thermodynamically based equation of state [Birch, 1978] such as used here.

\section{RESULTS}

In this section we use the data of seismology and mineral physics to test the hypothesis that the mantle is chemically homogeneous. The qualitative agreement between the locations and properties of the major seismic discontinuities and those expected in an olivine-rich mantle suggests that the discontinuities are due to phase changes [e.g., $A n$ derson, 1967, 1970]. It has been the prevailing view for 20 years that all mantle discontinuities are equilibrium phase changes in a homogeneous mantle. Since phase changes are the first-order effects and will occur regardless of whether the mantle is homogeneous or not, it is difficult to determine if the chemistry, as well as the mineralogy, changes across the mantle discontinuities. In previous sections we have attempted to assemble a self-consistent set of physical parameters of all the important mantle phases. The temperature and pressure derivatives and the rigidity and bulk modulus derivatives cannot be picked independently as has been the case in the past [e.g., Weidner, 1986; Bina and $W o o d, 1987]$. The resulting parameters included a $d G / d P$ for $\beta$ and $\gamma$ that is spinellike but a $d G / d T$ that is olivinelike, giving relations between these derivatives which are neither spinellike or olivinelike or, for that matter like any other relevant compound. Similarly, Bina and Wood pick temperature derivatives for the spinel phases which are not only abnormally high but also are anomalous, relative to any other compound when compared with the pressure derivatives [Anderson, 1988]. We suggest that the various temperature and pressure derivatives should be derived in a coherent self-consistent manner and independently of the requirements of a particular hypothesis. An alternative is to pick a petrological model and to determine what physical properties of the minerals are required [e.g., Weidner, 1986]. These properties should then be tested for plausibility, as a set. The latter is not generally done.

Mineral velocities as a function of depth are plotted along a $1400^{\circ} \mathrm{C}$ adiabat in Figures 6 and 7. Shown for comparison in Figure 6 are Earth models GCA [Walck, 1984] and CJF [Walck, 1985], while models TNA and SNA [Grand and Helmberger, 1984] are shown in Figure 7. Pressures were converted to depths using Earth model PREM. The iron content of all ferromagnesian silicates was taken to be $10 \mathrm{~mol} \%$ except for $\mathrm{Mg}$-rich garnets $(20 \mathrm{~mol} \%)$ and magnesiowüstite ( $30 \mathrm{~mol} \%)$.

The primary difference between our results and those of Bass and Anderson [1984] is due to the velocities of the majorite phases. Bass and Anderson used a measured bulk modulus [Jeanloz, 1981] substantially larger than subsequent measurements [Yagi et al., 1987; Weidner et al., 1987] and larger than one would expect from ${ }^{\mathrm{VI}}[\mathrm{MgSi}]$ for ${ }^{\mathrm{VI}} \mathrm{Al}_{2}$ substitution. Since the more recent measurements are in accord with expected garnet behavior and include highquality Brillouin data, we chose these lower estimates for this work. Velocities in pyrope and $\mathrm{Mg}$-rich majorite are now virtually indistinguishable. The $1-2 \%$ velocity difference between grossular and $\mathrm{Ca}$-rich majorite is largely due to differences in iron content and shows the effect of including $10 \mathrm{~mol} \mathrm{\%} \mathrm{Fe}$ in grossular. Both $\mathrm{Ca}$ - and $\mathrm{Mg}$-majorite are about $10-15 \%$ slower here than indicated by Bass and Anderson [1984]. Velocities in Na-rich majorite are similar in the two studies, but these are, nevertheless, highly uncertain. Bass and Anderson used their results to argue for a garnet- and clinopyroxene-rich upper mantle mineralogy. An important question, then, is whether such a mineralogy is still tenable, given that the properties of one of its major constituents has undergone substantial revision.

In the uppermost mantle (above $400 \mathrm{~km}$ ) there is considerable variation among different seismic models and a variety of mineral combinations can be used to match the seismic data. Olivine alone is in reasonably good agree- 


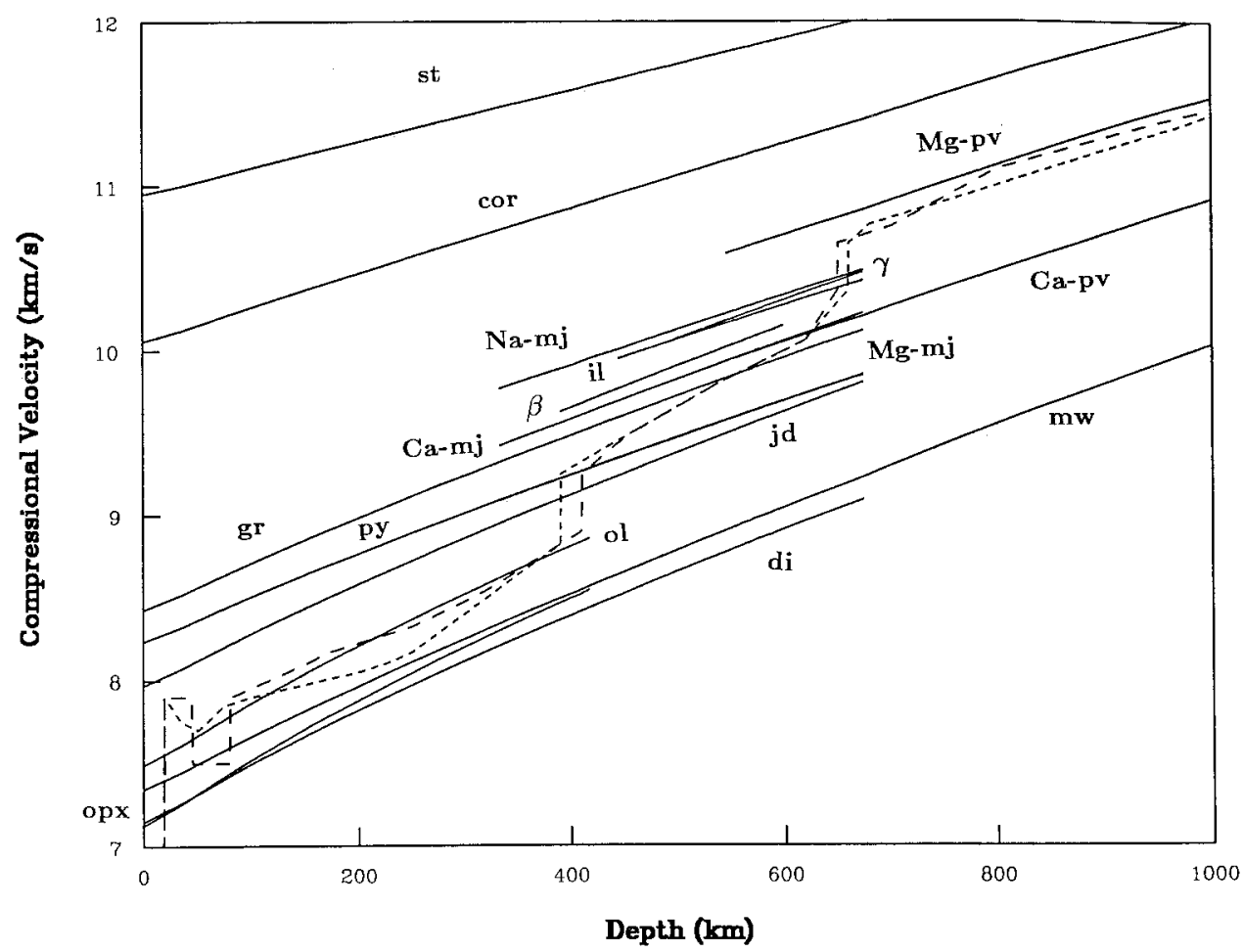

Fig. 6. Finite strain trajectories for $P$ wave velocity. The calculation is initiated along a $1400^{\circ} \mathrm{C}$ adiabat. Shown for comparison are Earth models GCA (short-dashed curve) and CJF (long-dashed curve). The abbreviations are $\mathrm{Mg}$-pv, $\mathrm{Mg}$-rich perovskite; Ca-pv, calcium-rich perovskite; il, ilmenite; $\mathrm{Mg}$-mj, $\mathrm{Mg}$-rich majorite; Ca-mj, $\mathrm{Ca}$-rich majorite; $\mathrm{Na}-\mathrm{mj}, \mathrm{Na}$-rich majorite; $\mathrm{gr}$, grossularite; jd, jadeite. Other abbreviations are the same as in Figure 5.

ment as is olivine combined with equal parts fast material (jadeite and garnet) and slow material (other pyroxenes) or garnet plus pyroxene (eclogite) with or without olivine. Thus this region does not provide any means to distinguish between petrological models. We must only require that the absolute value of the velocity in this region be matched by the petrological model and look for more stringent tests deeper in the Earth. Although olivine-rich garnet peridotite is consistent with the seismic velocities above 400 $\mathrm{km}$ and is a reasonable mineralogy based on other considerations, it is not required by the seismic data.

The $400-\mathrm{km}$ discontinuity provides an important constraint on the amount of olivine in the mantle since it is believed to be caused by the $\alpha-\beta$ transition. Insofar as olivine and its high-pressure phases are important components of the mantle, the properties of $\alpha$ and $\beta$ are important in discussions of the $400-\mathrm{km}$ discontinuity, even if it is not an equilibrium phase boundary in a homogeneous mantle. According to Figures 6 and 7 the velocities in the spinels are much higher than in olivine. This suggests that mineralogies which are not predominately olivine have a better chance of matching the size of the discontinuity and the velocities below $400 \mathrm{~km}$ than olivine-rich peridotites.

It is also clear that a broad phase transition or chemical gradient is required for the transition region since the slopes of the mineral trajectories are much lower than those observed seismically. This favors olivine- and orthopyroxene-poor mineralogies, since neither of these minerals can be responsible for a broad transition at these depths.
Velocities at the top of the lower mantle (to $1000 \mathrm{~km}$ depth) are consistent with the properties of perovskite but not with the high-pressure forms of olivine, in agreement with earlier studies [e.g., Butler and Anderson, 1978]. This suggests that the $670-\mathrm{km}$ discontinuity may represent a change in composition and a chemical barrier to whole mantle convection. Large amounts of Fe-rich magnesiowüstite are allowed only if there is some additional high-velocity material or the temperature derivatives of perovskite are much lower than those used here.

This study will stop short of a complete petrological inversion since its goal is to focus on the role of elasticity data. However, in analyzing our results it is important to bear in mind the main features of mantle phase equilibria. There have been a series of recent petrological studies which have clarified and, in some cases, revised our understanding of those systems believed to be most important in the upper mantle. Many of the most recent results have been summarized by Anderson and Bass [1986] and Irifune [1987].

Phase equilibria in the olivine system have been considered in several recent studies [Navrotsky and Akaogi, 1984; Fei and Saxena, 1986; Bina and Wood, 1987]. While there is some disagreement, the main features of olivine equilibria have become clear. The $\alpha$-phase of olivine transforms to $\beta$-spinel over a narrow pressure range at about $400 \mathrm{~km}$ depth. The $\beta-\gamma$ transition is spread over several gigapascals within the transition region. The olivine system and the resulting sound speeds will be considered in more detail below. 


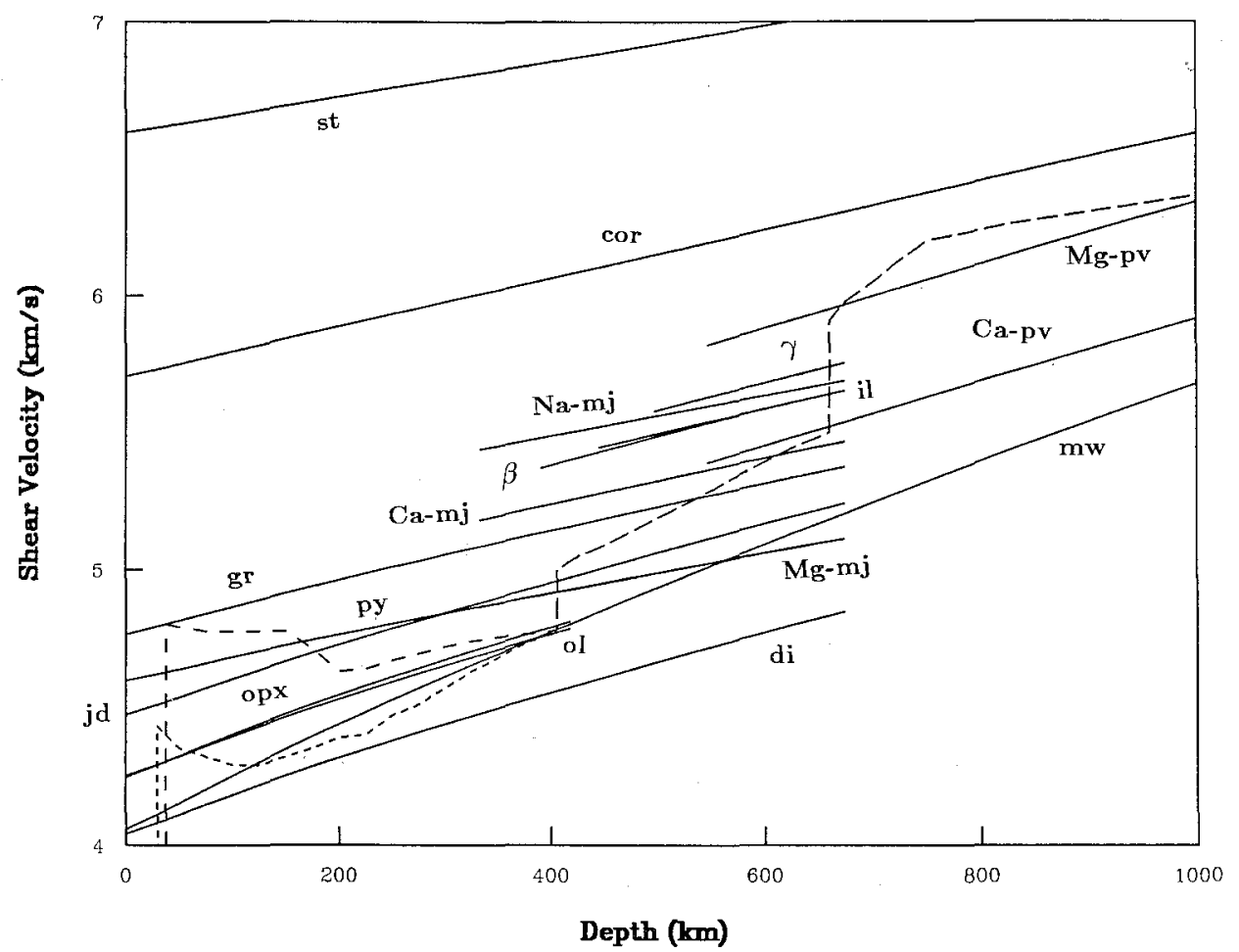

Fig. 7. Finite strain trajectories for $S$ wave velocity. Conditions are the same as in Figure 6. The Earth models in this case are TNA (short-dashed curve) and SNA (long-dashed curve). The abbreviations are the same as in Figures 5 and 6.

The pyroxene-garnet system is characterized by the dissolution of pyroxene into the garnet structure over a broad pressure interval. For Mg-rich pyroxenes the transformation to garnet is complete by about $400-450 \mathrm{~km}$ depth [Akaogi et al., 1987; Kanzaki, 1987]. Diopsidic pyroxene persists to greater depths [Akaogi and Akimoto, 1979; Ito and Takahashi, 1987], as does jadeite [Irifune, 1987], before dissolving into the garnet structure. Depending on temperature and $\mathrm{Al}_{2} \mathrm{O}_{3}$ and $\mathrm{FeO}$ contents, there may be a restricted field of ilmenite stability below $500 \mathrm{~km}$.

At greater depth, majorite or ilmenite transforms to perovskite over a large pressure interval. In addition, $\gamma$-spinel dissociates into perovskite and magnesiowüstite. These transformations may explain the seismic structure around $670 \mathrm{~km}$. In addition, a change in chemistry may also occur at this depth.

Using these basic phase equilibria as a guide, we can obtain estimates for the mineral proportions of the upper mantle by solving a series of linear equations at selected depths. The result, using the data of Figures 6 and 7, is that good agreement for both compressional and shear properties can be obtained from a starting low-pressure mineralogy of $40 \%$ olivine, $37 \%$ clinopyroxene, $13 \%$ garnet, and $10 \%$ orthopyroxene. The agreement deteriorates as more olivine is added to the mineralogy, particularly with regard to shear properties. This conclusion holds regardless of the depth or the adiabat initiation temperature. As we mentioned before, the shallow mantle can be much more olivine-rich. If so, the shallow mantle must differ in composition from the transition region as well as from the lower mantle.

\section{An Olivine Mantle}

Additional constraints on suitable petrological models can be obtained by considering the seismic behavior of a hypothetical pure olivine mantle. Seismic velocities were calculated as described above. Phase equilibria data were taken from the thermochemical calculation of Bina and Wood [1987]. In mixed phase regions, velocities were calculated by volume averaging using the Voigt-Reuss-Hill procedure.

The results of this calculation are shown in Figures 8 and 9. As before, iron content is $10 \%$, and the trajectory is initiated along a $1400^{\circ} \mathrm{C}$ adiabat. Earth models GCA and CJF (Figure 8) and TNA and SNA (Figure 9) are shown for comparison. It is evident from the figures that a pure olivine mantle produces a discontinuity much greater than observed seismically. High-resolution seismic models yield compressional velocity jumps at $400 \mathrm{~km}$ ranging from 3.9 to $5.1 \%$. The jump in a pure olivine mantle is $9.7 \%$. This indicates that a mineralogy with $40-53 \%$ olivine could match the velocity increase at $400 \mathrm{~km}$ if the other mantle components are passive near this depth. This is consistent with the mineralogy inferred in the previous section. For shear waves the jump in several recent high-resolution models is $4.6 \%$. For a pure olivine mantle we calculate a velocity increase of $13.0 \%$ for shear waves, indicating a mantle olivine content of $35 \%$. These results depend slightly on the method used for calculating the effect of temperature (equation (10) or (11) ). If equation (10) is used for temperature corrections, $5-10 \%$ less olivine is allowed in both cases. It should be noted that these numbers represent an upper limit for the olivine content since other phase trans- 


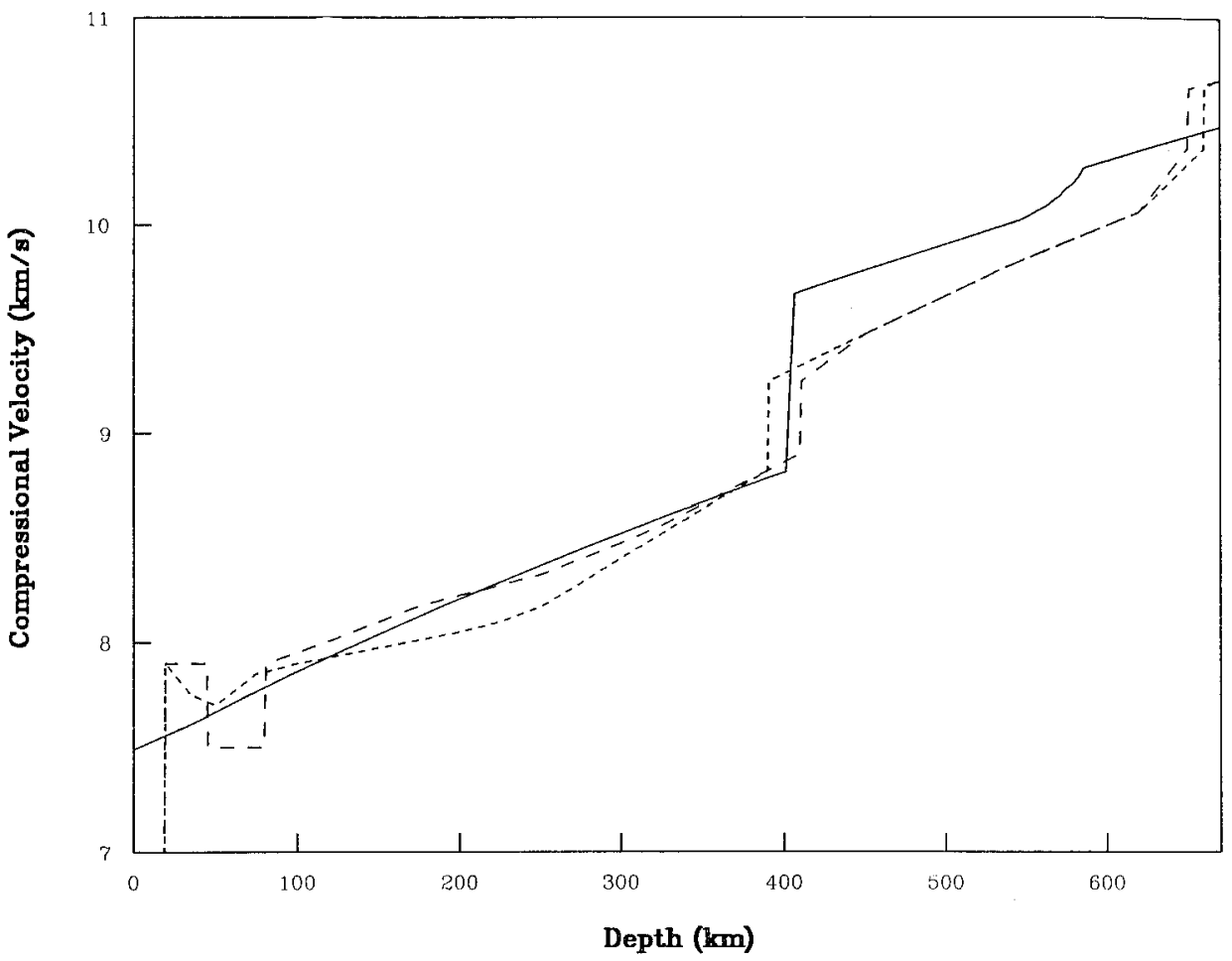

Fig. 8. Compressional velocity along a $1400^{\circ} \mathrm{C}$ adiabat for a hypothetical pure olivine mantle (solid curve) compared to Earth models GCA (short-dashed curve) and CJF (long-dahsed curve). The velocity increase near $400 \mathrm{~km}$ is substantially larger in the olivine model than in the Earth models. Mineralogies with $40-53 \%$ olivine by volume can satisfy the compressional velocity profiles.

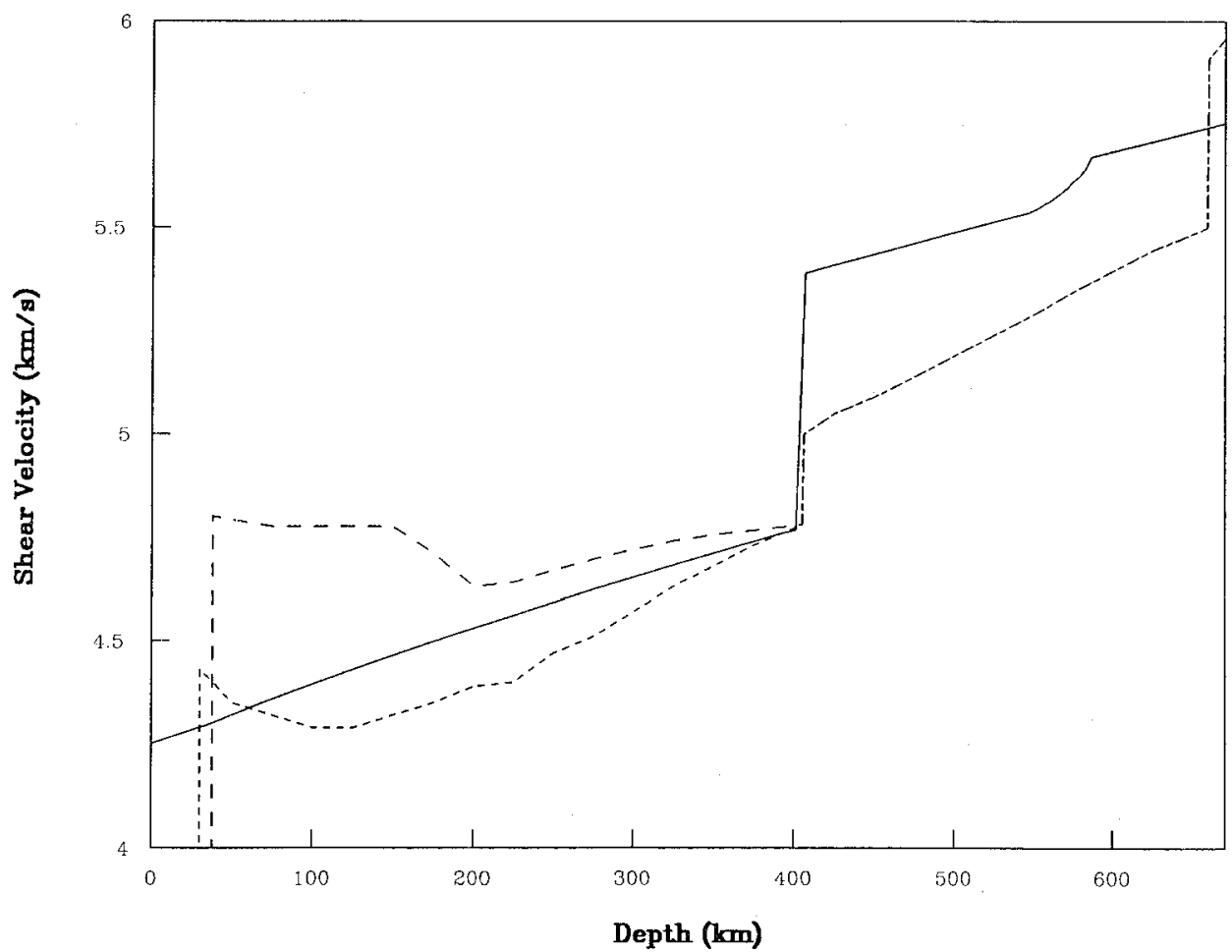

Fig. 9. Shear velocity along a $1400^{\circ}$ adiabat for a hypothetical pure olivine mantle compared to Earth models TNA (short-dashed curve) and SNA (long-dahsed curve). Shear velocity data are consistent with a mantle olivine content of only $35 \%$. Phase changes in the olivine component produce a net transition region gradient substantially smaller than that observed seismically. 


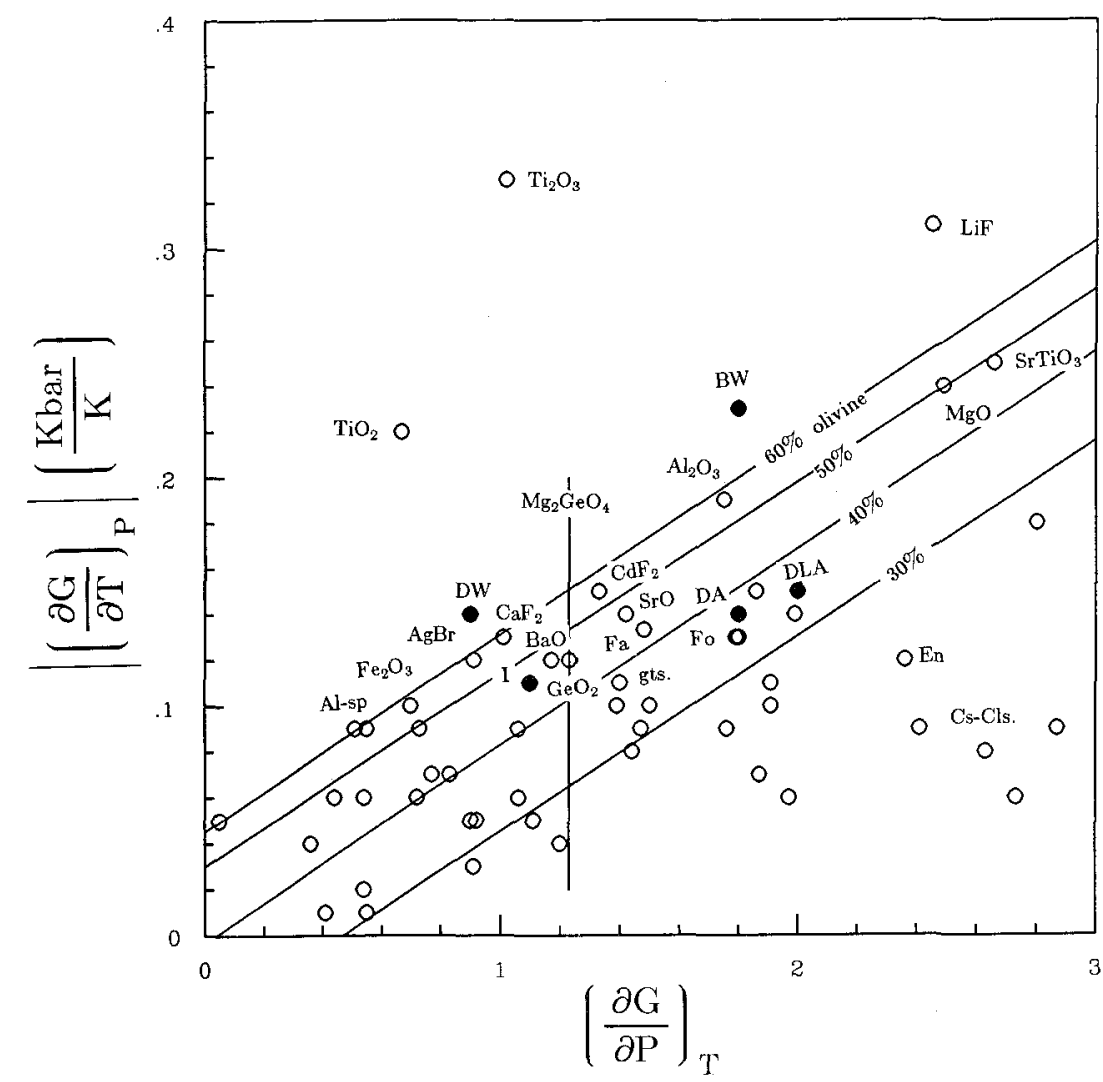

Fig. 10. Temperature derivative of the shear modulus plotted against pressure derivative of the shear modulus. Open circles represent measured values for 56 minerals. Solid circles are estimates of the properties of $\beta$-spinel in this and several other recent studies. Also shown are contours of allowed olivine content for given values of the shear derivatives of $\beta$-spinel. Germanate spinel $\left(\mathrm{Mg}_{2} \mathrm{GeO}_{4}\right)$ is indicated by a vertical line as its temperature derivative is unknown. Abbreviations are DW, Weidner [1986]; BW, Bina and Wood [1987]; I, Irifune [1987]; DLA, Anderson [1988]; DA, this study; Fo, forsterite; Fa, fayalite; En, enstatite; gts., garnets; CsCls., CsCl structures; $\mathrm{Al}-\mathrm{sp}, \mathrm{Al}_{2} \mathrm{MgO}_{4}$

formations such as orthopyroxene-majorite are occurring near the $400-\mathrm{km}$ discontinuity and will add to the velocity increase.

The transition zone gradient for the seismic profiles is $30-50 \%$ greater than for an olivine mantle. For a chemically homogeneous transition zone it is required that other phase transitions must be occurring in this region. $\mathrm{Ca}$ - and Na-rich clinopyroxenes undergo a broad transition to the majorite structure in this region.

Agreement between a pyrolite mantle and the seismic profiles is attainable at the $400-\mathrm{km}$ discontinuity by reducing the pressure derivatives of the shear moduli of the spinel phases or by increasing their temperature derivatives. The magnitudes of these adjustments, however, are large enough that the resulting estimates are in violation of the systematics discussed above. Lowering the pressure derivatives makes the transition zone gradient more difficult to match and more clinopyroxene is required (or a stronger compositional gradient). Of course, it is possible to reduce the magnitude of the adjustments by simultaneonsly reducing the pressure derivative and increasing the temperature derivative. But this is a violation of equation (4) and is therefore inconsistent with the trends in the elasticity data set.

The amount of olivine/ $\beta$-spinel allowed by the seismic shear wave profiles depends on the values of $G^{\prime}=\partial G / \partial$
$P$ and $\dot{\mathrm{G}}=|\partial G / \partial T|$ adopted for $\beta$-spinel since the other required parameters for olivine and $\beta$-spinel are known. Figure 10 shows contours of allowed olivine content as a function of $G^{\prime}$ and $\dot{G}$ for $\beta$-spinel based on matching the size of the $400-\mathrm{km}$ discontinuity in shear wave profiles. Also shown are the 55 minerals for which data on both $G^{\prime}$ and $\dot{G}$ exist. In addition, estimates used in this and other recent studies are included.

Contours were determined by comparing the shear wave velocity of olivine just above the $400-\mathrm{km}$ discontinuity with the velocity of $\beta$-spinel just below it. The values of the contours are insensitive to the choice of bulk modulus derivatives. Olivine contents of $60 \%$ or more are allowed if the spinel shear derivatives are at the edge of the bulk of the data [e.g., Bina and Wood, 1987; Weidner, 1986].

Aluminate spinel, a relatively poor analogue, is the only relevant material which has derivative properties consistent with an olivine content of greater than $50 \%$. The silicate subset of the parameters, including forsterite, falls within the region of $40 \%$ or less olivine. While the estimates of Bina and Wood are not similar to any other material, the estimates of Weidner and Irifune fall in the range of materials with large ionic radius $\left(\mathrm{AgBr}, \mathrm{CaF}_{2}\right.$, $\mathrm{CdF}_{2}, \mathrm{SrO}, \mathrm{GeO}_{2}$, and $\mathrm{BaO}$ ) and transition metal ions $\left(\mathrm{Fe}_{2} \mathrm{O}_{3}, \mathrm{Fe}_{2} \mathrm{SiO}_{4}\right)$. These materials are much poorer analogues for $\beta$-spinel than olivine and other $\mathrm{Mg}$-rich silicates. 
TABLE 3. Summary of the Elastic Properties of the Olivine Phases

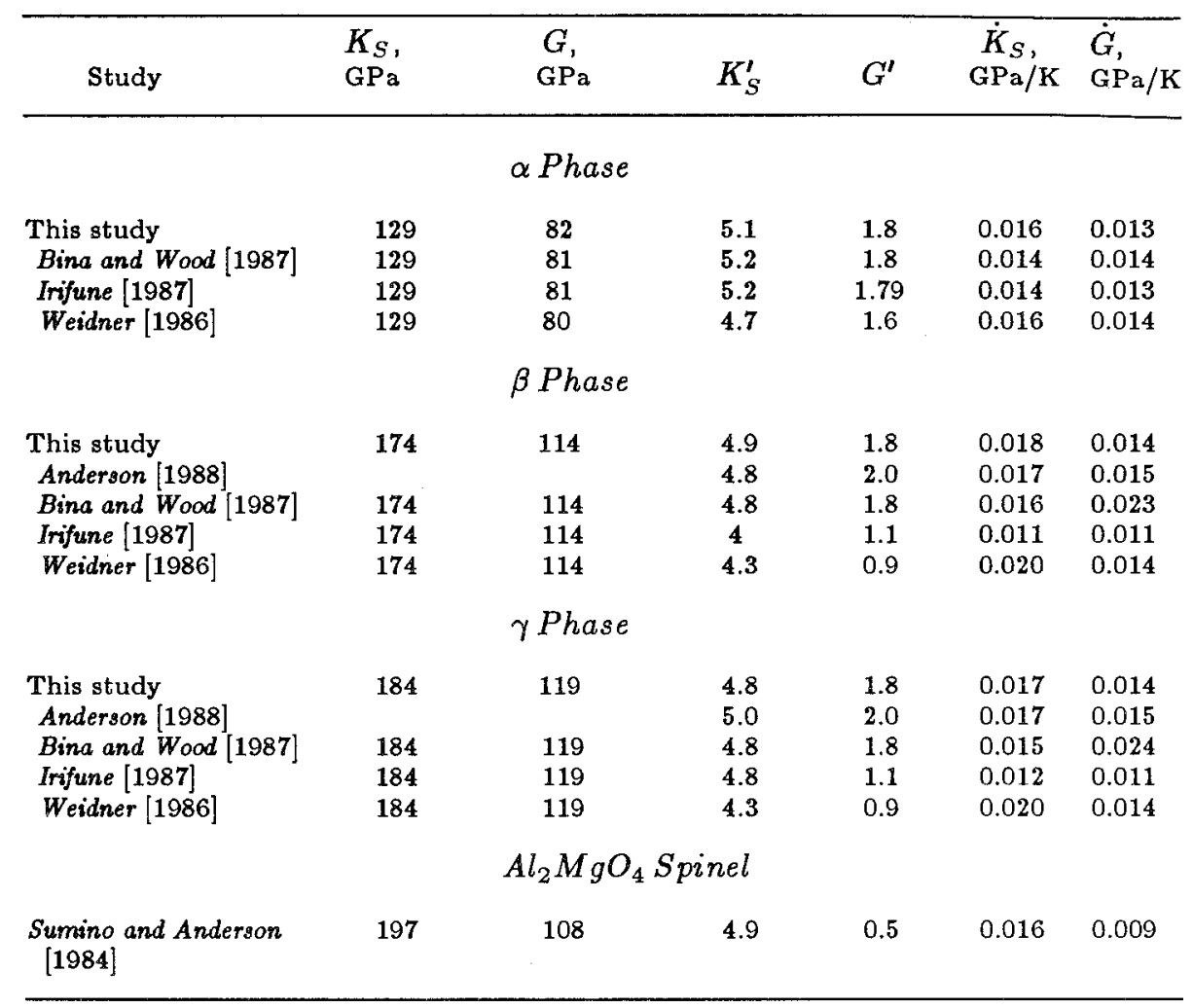

On the basis of ionic considerations it is unlikely that $G^{\prime}$ for silicate spinel is as low as $G^{\prime}$ for germanate spinel. If, however, this value is used for $G^{\prime}$ and $\dot{G}$ is adopted from aluminate spinel, then the result is in the field of less than $40 \%$ olivine. Using our temperature systematics, however, we would predict $\dot{G}$ to be no more than 0.12 for germanate spinel, yielding an olivine content of at most $50 \%$. If $\dot{G}$ is 0.15 or larger, an olivine-rich $(>60 \%)$ mantle would be required. Thus an olivine-rich mantle is possible if $\beta$-spinel violates the trends observed in the data set. Our preferred values, however, are consistent with an olivine content of $40 \%$ or less.

On the basis of elasticity systematics for temperature and pressure derivatives we conclude that mineralogies with a maximum olivine content of about $35-53 \%$ produce the best agreement with the seismic profiles. Compressional velocity profiles seem to allow about $10 \%$ more olivine than shear profiles, and the reason for this difference needs to be more fully investigated. Both compressional and shear seismic profiles are well matched by mineralogies containing about $40 \%$ olivine and a substantial amount of $\mathrm{Ca}$-rich and, possibly, Na-rich clinopyroxenes.

\section{Discussion}

The results obtained here disagree with a number of recent studies which have supported an olivine-rich model for the upper mantle [Weidner, 1986; Irifune, 1987; Bina and Wood, 1987]. The primary cause of the disagreement rests in the values used for the derivatives of spinel phases and differences in the equations of state used. Table 3 compares the elastic properties used for the $\alpha, \beta$, and $\gamma$ phases in this and other recent studies. In studies supporting a mineralogy with $60-70 \%$ olivine the derivatives of the spinel phases are chosen such that sound speeds, particularly shear velocity, in spinel and olivine converge at high pressure and temperature. This is accomplished either through very high temperature derivatives for the spinels [Bina and Wood, 1987] or very low pressure derivatives [Weidner, 1986; Irifune, 1987]. If the derivatives of the spinel phases are chosen to be similar to olivine, a relatively olivine-poor mineralogy best matches the seismic profiles.

The elastic properties of $\mathrm{Al}_{2} \mathrm{MgO}_{4}$-spinel are also given in Table 3. This material has a high $K_{S} / G$ relative to the silicate spinels and, from Figure 2, is therefore expected to have a lower $(\partial G / \partial P)_{T}$. The low $(\partial G / \partial P)_{T}$ of $\mathrm{Al}_{2} \mathrm{MgO}_{4}$ is sometimes used as an argument in favor of a low $(\partial G / \partial P)_{T}$ for silicate spinels such as used by Weidner [1986] and Irifune [1987]. Note, however, that $\mathrm{Al}_{2} \mathrm{MgO}_{4}$ also has a low $(\partial G / \partial T)_{P}$. In addition, Figures 2 and 4 show that crystal structure does not constrain the derivatives.

Low measured pressure derivatives for aluminate spinels have been used as justification for low pressure derivatives for silicate spinels. However, it was shown above that aluminate spinels are poor analogues for silicate spinels. Aluminate and silicate spinels do not even satisfy the same systematics for the first-order elastic constants. Furthermore, measured compressional and shear wave velocities in silicate spinels do not converge at high pressure [Fujisawa, 1987].

A recent measurement of the pressure derivatives of germanate spinel $\left(\mathrm{Mg}_{2} \mathrm{GeO}_{4}\right)$ has yielded smaller pressure 
derivatives than used here for silicate spinels [Rigden et al., 1988] but higher values than $\mathrm{Al}_{2} \mathrm{MgO}_{4}$-spinel. IV $\mathrm{Ge}^{4+}$ has an ionic radius between ${ }^{\mathrm{IV}} \mathrm{Mg}^{2+}$ and ${ }^{\mathrm{IV}} \mathrm{Si}^{4+}$, and $\mathrm{Mg}_{2} \mathrm{GeO}_{4}$-spinel has a $K_{S} / G$ between that of $\mathrm{Al}_{2} \mathrm{MgO}_{4}$ and $\beta$-spinel. Therefore on the basis of relations developed here and by Anderson [1988] we expect $\beta$-spinel to have $(d G / d P)_{T}$ appreciably greater than $\mathrm{Mg}_{2} \mathrm{GeO}_{4}$-spinel, consistent with our choice. For other isostructural compounds an increase in $K_{S} / G$ as large as that between $\mathrm{Mg}_{2} \mathrm{GeO}_{4}-$ spinel and $\mathrm{Mg}_{2} \mathrm{SiO}_{4}$-spinel gives a normalized pressure derivative of the rigidity, $\{G\}_{T}=K_{T}(d G / d P)_{T} / G$ that is $50 \%$ to a factor of 2 larger [Anderson, 1988]. A decrease in cation radius, comparable to the decrease from $\mathrm{Ge}^{4+}$ to $\mathrm{Si}^{4+}$, gives an increase in $\{G\}_{T}$ of about 30 to $40 \%$, in agreement with our values. Weidner and Hamaya [1983], however, caution that germanate spinels may not be good analogues for silicate spinels.

As a test of the predictive ability of our systematics, the data of Figs. 1 and 2 were used to estimate a priori the properties of germanate spinel. Our predicted bulk modulus pressure derivative $\left(K^{\prime}=4.75\right)$ is $13 \%$ greater than measured $\left(K^{\prime}=4.2\right)$. This level of uncertainty is probably typical for our bulk modulus estimates, particularly for cases such as germanate spinel which differ markedly from aluminate spinels in such properties as $\mathrm{Mg}^{+}$coordination, density, and jonic radii. Our prediction for the shear modulus pressure derivative ranges between 1.05 and 1.25 which is in agreement with the measured value $\left(G^{\prime}=1.2\right) . G^{\prime}$ of germanate spinel is the same as that of $\mathrm{GeO}_{2}$, the only other Ge-bearing mineral in the data set. This further illustrates the importance of chemistry in determining $G^{\prime}$. That $K_{S}^{\prime}$ for $\mathrm{GeO}_{2}$ is high and typical of a rutile is indicative of the more important role of structure in $K_{S}^{\prime}$.

Most of the previous investigators agree on most of the parameters (Table 3). Bina and Wood [1987] choose extremely high temperature derivatives for the spinel phases which means they disagree with the other studies including Weidner [1986] on the moduli of $\beta$ and $\gamma$ at high temperature. The fact that they agree with Weidner [1986] at high pressure is entirely fortuitous and is a result of Weidner's low pressure derivatives for the spinel phases combined with normal temperature derivatives. Bina and Wood and Weidner's results would also differ at high pressure at a lower temperature. The extreme values adopted by Bina and Wood [1987], Irifune [1987], and Weidner [1986] for one parameter or another might be rationalized by recognizing that some compound can be found with such parameters. However, an extreme temperature derivative combined with a normal pressure derivative, or vice verse, is unlikely and when these cases occur they are accompanied by other unusual characteristics such as $K_{S} / G$ or Grüneisen parameter. The spinel forms of olivine do not display extreme behavior in any of their measured properties.

Sawamoto et al. [1984] also suggested that the olivine content of the mantle may be about $40 \%$. They based this on the difference in velocities between $\alpha$ and $\beta$ under ambient laboratory conditions. Sawamoto et al. [1984, p.751] pointed out that "if the pressure derivatives of the bulk modulus and the shear modulus for the beta phase are approximately 3.9 and 1.1 then the observed discontinuity is consistent with a pyrolite composition." These are much lower than the estimates in this paper and estimates of others (Table 3). Such low values, particularly relative to olivine, are difficult to justify on any physical or empirical grounds.

High shear temperature derivatives for the spinels are not justified by consideration of the temperature derivatives for any likely analogue (olivine, aluminate spinel). The justification given by Bina and Wood [1987] was that $\partial \ln K_{S} / \partial T$ is approximately constant for a subset of mantle minerals and therefore $\partial \ln G / \partial T$ was assumed to be constant across phase changes. This produces very large temperature derivatives for high-pressure phases. Anderson [1988] has shown from consideration of a larger elasticity data set that neither of the above quantities is constant for any particular structure. Thus there is little justification for selecting anomalously high $\dot{G}$ for spinels. In fact, $d G / d T$ is more constant than $\partial \ln G / d T$, in agreement with our values and Weidner's [1986] $d G / d T$ values.

The study of Irifune [1987] also deserves some comment. While Irifune concludes that pyrolite is a good match to the envelope of seismic profiles, it is clear from his figures that he does not obtain good agreement with any particular seismic profile. His envelope of seismic models is not a good test for a mineralogical model since it mixes both high- and low-resolution models and includes one model no longer considered to be valid. Virtually any proposed mineralogy would fall within such an envelope. When compared to a particular model, Irifune's pyrolite model produces velocity increases at $400 \mathrm{~km}$ that are far greater than observed seismically despite that fact that low-pressure derivatives for spinels were used in his study. This illustrates the fact that the orthopyroxene-majorite transition can add significantly to the velocity increase near $400 \mathrm{~km}$. Transition zone gradients produced by Irifune and other workers as well (Bina and Wood, in particular) are much lower than observed.

\section{CONCLUSIONS}

In this study, existing elasticity data for mantle minerals have been compiled and evaluated. Estimates of unmeasured derivatives are obtained from trends distilled from a large elasticity data base. The bulk modulus pressure derivative can be obtained from compression or analogue data, complemented by several trends found in the data set. The shear modulus pressure derivative is a function of $K_{S} / G$. Temperature derivatives can be obtained from dimensionless logarithmic anharmonic parameters.

By combining these properties with appropriate temperature corrections and finite strain theory, mineral velocities as a function of depth were obtained. Both compressional and shear velocities are well matched by a mineralogy consisting of $40 \%$ olivine, $37 \%$ clinopyroxene, $13 \%$ garnet, and $10 \%$ orthopyroxene. For comparison, pyrolite is approximately $61 \%$ olivine, $15 \%$ orthopyroxene, $14 \%$ garnet, and $10 \%$ clinopyroxene. Alternatively, the mantle above $400 \mathrm{~km}$ can be olivine- and orthopyroxene-rich, and the transition region can be poorer in these minerals. The properties of a pure olivine mantle were also considered. The discontinuity at $400 \mathrm{~km}$ is matched by a mineralogy with a maximum of $35 \%$ olivine for shear waves and $40-$ $53 \%$ olivine for compressional waves. The transition zone gradient is poorly matched by an olivine mantle. 
Previous studies which allow larger proportions of olivine differ from this study in the form of the equation of state and in the shear derivatives of the spinel phases. The derivatives adopted in these studies are difficult to justify based on analogue data and the trends exhibited in the full data set. By deriving and using a self-consistent set of parameters we conclude that a mineralogy with about $40 \%$ olivine and relatively garnet- and clinopyroxene-rich best matches the seismic profiles. Due to uncertainties in elasticity estimates, equations of state, and seismic profiles, however, a mantle with either more or less olivine cannot be ruled out at present.

Acknowledgments. We would like to thank Jean-Paul Montagner, Ian Jackson, and Don Weidner for useful discussion and comments. This research was supported by the National Science Foundation grant EAR-8509350. Contribution 4619, Division of Geological and Planetary Sciences, California Institute of Technology, Pasadena, California.

\section{REFERENCES}

Akaogi, M., and S. Akimoto, High pressure phase equilibria in a garnet lherzolite with special references to $\mathrm{Mg}^{2+}-\mathrm{Fe}^{2+}$ partitioning among constituent minerals, Phys. Earth Planet. Inter., 19, 31-51, 1979.

Akaogi, M., A. Navrotsky, T. Yaki, and S. Akimoto, Pyroxenegarnet transformation: Thermochemistry and elasticity of garnet solid solutions and application to mantle models, in High-Pressure Research in Mineral Physics, Geophys. Monogr. Ser., vol. 39, edited by $M$. H. Manghnani and Y. Syono, pp. 251260, AGU, Washington, D.C., 1987.

Anderson, D. L., Phase change in the upper mantle, Science, 157, 1165-1173, 1967.

Anderson, D. L., Petrology of the mantle, Spec. Pap. Minenal. Soc. Am., s, 85-93, 1970.

Anderson, D. L., Estimation of elastic properties of oxides and silicates (abstract), Eos Thans. AGU, 67, 374, 1986.

Anderson, D. L., Temperature and pressure derivatives of elastic constants with application to the mantle, J. Geophys. Res., 99, 4688-4700, 1988.

Anderson, D. L., and O. L. Anderson, The bulk modulus volume relationsip for oxides, J. Geophys. Res., 75, 3494-3500, 1970.

Anderson, D. L., and J. D. Bass, Mineralogy and composition of the upper mantle, Geophys. Res. Lett., 11, 637-640, 1984.

Anderson, D. L., and J. D. Bass, Transition region of the Earth's upper mantle, Nature, 920, 321-328, 1986.

Anderson, O. L., Comments on the negative pressure dependence of the shear modulus found in some oxides, J. Geophys. Res., 79, 7707-7712, 1968.

Anderson, O. L., A scaling law for $\mathrm{K}_{O}$ ' for silicates with constant mean atomic mass, Earth Planet. Sci. Lett., 20, 73-76, 1973.

Bass, J. D., Elasticity of single-crystal $\mathrm{SmAlO}_{3}, \mathrm{GdAlO}_{3}$ and $\mathrm{ScAlO}_{3}$ perovskites, Phys. Earth Planet. Inter., 96, 145-156, 1984.

Bass, J. D., Elasticity of uvarovite and andradite garnets, $J$. Geophys. Res., 91, 7505-7516, 1986.

Bass, J. D., and D. L. Anderson, Composition of the upper mantle: Geophysical tests of two petrological models, Geophys. Res. Lett., 11, 237-240, 1984.

Bass, J. D., and D. J. Weidner, Elasticity of single-crystal orthoferrosilite, J. Geophys. Res., 89, 4359-4371, 1984.

Bass, J. D., D. J. Weidner, N. Hamaya, M. Ozima, and S. Akimoto, Elasticity of the olivine and spinel polymorphys of $\mathrm{Ni}_{2} \mathrm{SiO}_{4}$, Phys. Chem. Miner., 10, 261-272, 1984.

Bina, C. R., and B. J. Wood, Olivine-Spinel transitions: Experimental and thermodynamic constraints and implications for the nature of the 400-km seismic discontinuity, J. Geophys. Res., 92, 4853-4866, 1987.

Birch, $F_{\text {, }}$ Elasticity and constitution of the Earth's interior, $J$. Geophys. Res., 57, 227-285, 1952.

Birch, F., Finite strain isotherm and velocities for single-crystal and polycrystalline $\mathrm{NaCl}$ at high pressure and $300^{\circ} \mathrm{K}, J$. Geophys. Res., 89, 1257-1268, 1978.

Burdick, L., and D. L. Anderson, Interpretation of velocity profiles of the mantle, J. Geophys. Res., 80, 1070-1074, 1975.

Butler, R., and D. L. Anderson, Equation of state fits to the lower mantle and outer core, Phys. Earth Planet. Inter., 17, 147-162, 1978.

Cameron, M., S. Sueno, C. T. Prewitt, and J. J. Papike, High temperature crystal chemistry of acmite, diopside, hedenbergite, jadeite, spodumene, and ureyite, Am. Mineral., 58, 594$618,1973$.

Chung, D. H., On the equations of state of high-pressure solid phases, Earth Planet. Sci. Lett., 18, 125-132, 1973.

Davies, G.F., The estimation of elastic properties from analogue compounds, Geophys. J. R. Astron. Soc., H, 625-647, 1976.

Davies, G. F., and A. M. Dziewonski, Homogeneity and constitution of the Earth's lower mantle and outer core, Phys. Earth Planet. Inter., 10, 336-343, 1975.

Deganello, S., The thermal expansion of diopside, Z. Kristallogr., 197, 127-131, 1973.

Duffy, T. S., and M. T. Vaughan, Elasticity of enstatite and its relationship to crystal structure, J. Geophys. Res., 9s, 383-391, 1988

Dziewonski, A. M., and D. L. Anderson, Preliminary reference Earth model, Phys. Earth Planet. Int., 25, 297-356, 1981.

Fei, Y., and S. K. Saxena, A thermochemical data base for phase equilibria in the system Fe-Mg-Si-O at high pressure and temperature, Phy. Chem. Miner., 1S, 311-324, 1986.

Finger, L. W., and Y. Ohashi, The thermal expansion of diopside to $800^{\circ} \mathrm{C}$ and a refinement of the crystal structure at $700^{\circ} \mathrm{C}$, Am. Mineral., 61, 303-310, 1976.

Frisillo, A. L., and G. R. Barsch, Measurement of single-crystal elastic constants of bronzite as a function of pressure and temperature, J. Geophys. Res., 77, 6360-6384, 1972.

Fujisawa, H., No olivine in the mantle? (abstract), Eos Trans. $A G U, 68,409,1987$.

Graham, E. K., and H. S. Kim, The bulk modulus of wustite (FeO) (abstract), Eos Trans. $A G U, 67,1240,1986$.

Graham, E. K., S. M. Sopkin, and W. E. Resley, Elastic constants of fayalite, $\mathrm{Fe}_{2} \mathrm{SiO}_{4}$ and the olivine solution series (abstract), Eos Trans. AGU, 69, 1090, 1982.

Grand, S. P., and D. V. Helmberger, Upper mantle shear structure of North America, Geophys. J. R. Astron. Soc., 76, 399-438, 1984.

Halleck, P. M., The compression and compressibility of grossularite garnet: A comparison of X-ray and ultrasonic methods, Ph. D. thesis, Univ. of Chicago, Chicago, Il., 1973.

Haniford, V. M., and D. J. Weidner, Elastic properties of grossular-andradite garnets $\mathrm{Ca}_{3}(\mathrm{Al}, \mathrm{Fe}) \mathrm{Si}_{3} \mathrm{O}_{12}$ (abstract), Eos Trans. $A G U, 66,1063,1985$.

Irifune, T., An experimental investigation of the pyroxenegarnet transformation in a pyrolite composition and its bearing on the constitution of the mantle, Phys. Earth Planet. Inter., 45, 324-336, 1987.

Isaak, D., and O. L. Anderson, The high temperature and thermal expansion properties of a grossular garnet (abstract), Eos Trans. $A G U, 68,410,1987$.

Ito, $E$, and $\mathbf{E}$. Takahashi, Ultrahigh-pressure phase transformation and the constitution of the deep mantle, High-Pressure Research in Mineral Physics, Geophys. Monogr. Ser., vol. 39, edited by M. H. Manghnani and Y. Syono, pp. 221-229, AGU, Washingtion, D.C., 1987.

Ito, H., K. Kawada, and S. Akimoto, Thermal expansion of stishovite, Phys. Earth Planet. Inter., 8, 277-281, 1974.

Jeanloz, R., Majorite: Vibrational and compressional properties of a high-pressure phase, J. Geophys. Res., 86, 6171-6179, 1981.

Jeanloz, R., and E. Knittle, Reduction of mantle and core properties to a standard state by adiabatic decompression, in Chemistry and Physics of the Terrestrial Planets, edited by S. K. Saxena, pp. 275-309, Springer-Verlag, New York, 1986.

Jeanloz, R., and A. B. Thompson, Phase transitions and mantle discontinuities, Rev. Geophys., 21, 51-74, 1983.

Jones, L., High-temperature behavior of the elastic moduli of $\mathrm{LiF}$ and $\mathrm{NaF}$ : Comparison with $\mathrm{MgO}$ and $\mathrm{CaO}$, Phys. Earth Planet. Inter., 19, 105-118, 1976.

Kandelin, J., and D. J. Weidner, The single-crystal elastic prop- 
erties of jadeite, Phys. Earth Planet. Inter., 50, 251-260, 1988 a.

Kandelin, J., and D. J. Weidner, Elastic properties of hedenbergite, J. Geophys. Res., 9s, 1063-1072, 1988 b.

Kanzaki, M., Ultra high-pressure phase relations in the system $\mathrm{Mg}_{4} \mathrm{Si}_{4} \mathrm{O}_{12}-\mathrm{Mg}_{3} \mathrm{Al}_{2} \mathrm{Si}_{3} \mathrm{O}_{12}$, Phys. Earth Planet. Inter., 49, 168-175, 1987.

Knittle, E., and R. Jeanloz, Synthesis and equation of state of $(\mathrm{Mg}, \mathrm{Fe}) \mathrm{SiO}_{3}$ perovskite to over 100 gigapascals, Science, 295, 668-670, 1987.

Knittle, E., R. Jeanloz, and G. L. Smith, Thermal expansion of silicate perovskite and stratification of the Earth's mantle, Nature, 919, 214-216, 1986.

Lees, A. C., M. S. T. Bukowinski, and R. Jeanloz, Reflection properties of phase transition and compositional change models of the 670-km discontinuity, J. Geophys. Res., 88, 8145-8159, 1983.

Levien, L., and C. T. Prewitt, High pressure structural study of diopside, Am. Mineral., 66, 315-323, 1981.

Levien, L., C. T. Prewitt, and D. J. Weidner, Compression of pyrope, Am. Mineral., 64, 805-808, 1979.

Liu, L., and W. A. Bassett, Elements, Oxides, Slicates: HighPressune Phases With Implications for the Earth's Interior, 250 pp., Oxford Press, New York, 1986.

Navrotsky, A., and $\mathbf{M}$. Akaogi, The $\alpha, \beta, \gamma$ phase relations in $\mathrm{Fe}_{2} \mathrm{SiO}_{4}-\mathrm{Mg}_{2} \mathrm{SiO}_{4}$ and $\mathrm{Co}_{2} \mathrm{SiO}_{4}-\mathrm{Mg}_{2} \mathrm{SiO}_{4}$ : Calculation from thermochemical data and geophysical applications, $J$. Geophys. Res., 89, 10,135-10,140, 1984.

Ridgen, S.M., I. Jackson, H. Niesler, A. E. Ringwood, and R. C. Libermann, Pressure dependence of the elastic wave velocities for $\mathrm{Mg}_{2} \mathrm{SiO}_{4}$ spinel to $3 \mathrm{GPa}$. Geophys. Res. Lett., 15, 605-608, 1988.

Ringwood, A. E., Composition and Petrology of the Earth's Mantle, 618 pp., McGraw-Hill, New York, 1975.

Robie, R. A., P. M. Bethke, M. S. Toulmin, and J. L. Edwards, $\mathrm{X}$-ray crystallographic data, densities, and molar volumes of minerals, in Handbook of Physical Constants, edited by S. P. Clark, pp. 27-74, Geological Society of America, Boulder, Colo., 1966.

Sato, Y., M. Akaogi, and S. Akimoto, Hydrostatic compression of the synthetic garnets pyrope and almandite, $J$. Geophys. Res., 8s, 335-338, 1978.

Sawamoto, H., D. J. Weidner, S. Sasaki, M. Kumazawa, Singlecrystal elastic properties of the modified spinel (beta) phase of magnesium orthosilicate, Science, 224, 749-751, 1984.

Sawamoto, H., M. Khozaki, S. Tanaka, A. Fujimura, and T. A kamatue, Fine measurements of compressibility fcr $\beta$. and $\gamma-\mathrm{Mg}_{2} \mathrm{SiO}_{4}$ at pressure up to 6 GPA using synchrotron radiation (abstract), IUGG Abstracts, vol. 1, p. 347, I.U.G.G. Publications Office, Paris, 1987.

Schwab, J. A., and E. K. Graham, Pressure and temperature dependence of the elastic properties of fayalite (abstract), Eos Trans. AGU, 64, 847, 1983.

Spetzler, H., 1, The effect of temperature and partial melting on velocity and attenuation in a single binary system, 2, Effect of temperature and pressure on the elastic properties of single crystal MgO, PhD. thesis, 245 pp., Calif. Instit. of Technol., Pasadena, Ca., 1969.

Spetzler, H., C. G. Sammis, and R. J. O'Connell, Equations of state of $\mathrm{NaCl}$ : Ultrasonic measurements to $8 \mathrm{kbar}$ and $800^{\circ} \mathrm{C}$ and static lattice theory, J. Phys. Chem. Solids, $99,1727-1750$, 1972.

Sumino, Y., The elastic constants of $\mathrm{Mn}_{2} \mathrm{SiO}_{4}, \mathrm{Fe}_{2} \mathrm{SiO}_{4}$ and $\mathrm{CO}_{2} \mathrm{SiO}_{4}$ and the elastic properties of olivine group minerals at high temperature, J. Phys. Earth, 27, 209-238, 1979.

Sumino, Y., and O. L. Anderson, Elastic constants of minerals, in Handbook of Physical Properties of Rocks, vol. III, edited by R. S. Carmichael, pp. 39-137, CRC Press, Boca Raton, Fla., 1984.

Sumino, Y., O. L. Anderson, and I. Suzuki, Temperature coefficients of elastic constants of single crystal $\mathrm{MgO}$ between 80 and $1300 \mathrm{~K}$, Phys. Chem. Miner., 9, 38-47, 1983.

Suzuki, I., Thermal expansion of periclase and olivine and their anharmonic properties, J. Phys. Earth, 29, 145-159, 1975 a.
Suzuki, I., Cell parameters and linear thermal expansion coefficients of orthoproxenes, J. Seismol. Soc. Jpn; 28, 1-9, $1975 b$.

Suzuki, I., and O.L. Anderson, Elasticity and thermal expansion of a natural garnet up to $1000 \mathrm{~K}, J$. Phys. Earth, 91, 125-138, 1983.

Suzuki, I., E. Ohtani, and M. Kumazawa, Thermal expansion of $\gamma-\mathrm{Mg}_{2} \mathrm{SiO}_{4}$, J. Phys. Earth, 27, 53-61, $1979 a$.

Suzuki, I., S. Okajima, and K. Seya, Thermal expansion of single-crystal manganosite, J. Phys. Earth, 27, 63-69, 1979 b.

Suzuki, I., E. Ohtani, and M. Kumazawa, Thermal expansion of modified spinel, $\beta-\mathrm{Mg}_{2} \mathrm{SiO}_{4}$, J. Phys. Earth, 28, 273-280, 1980

Suzuki, I., O. L. Anderson, and Y. Sumino, Elastic properties of a single-crystal forsterite $\mathrm{Mg}_{2} \mathrm{SiO}_{4}$, up to $1200 \mathrm{~K}$, Phys. Chem. Miner., 10, 38-46, 1983.

Wachtman, J. B., T. G. Scuderi, and G. W. Cleek, Linear thermal expansion of aluminum oxide and thorium oxide from 100 to 1100 K, J. Am. Ceram. Soc., 45, 319-323, 1962.

Walck, M. C., The P-wave upper mantle structure beneath an active spreading center: The Gulf of California, Geophys. J. R. Astron. Soc., 76, 697-723, 1984

Walck, M. C., The upper mantle beneath the north-east Pacific rim: A comparison with the Gulf of California, Geophys. J. $R$. Astron. Soc., 81, 243-276, 1985.

Watt, J. P., G. F. Davies, and R. J. O'Connell, The elastic properties of composite materials, Rev. Geophys., 14, 541-563, 1976.

Webb, S. L., and I. Jackson, The anomalous pressure dependence of the elastic moduli for single-crystal orthopyroxene (abstract), Eos Trans. $A G U, 66,371,1985$.

Weidner, D. J., Mantle model based on measured physical properties of minerals, in Chemistry and Physics of Terrestrial Planets, edited by S. K. Saxena, pp. 251-274, Springer-Verlag, New York, 1986.

Weidner, D. J., Mineral physics constraints on a uniform mantle composition, in High-Pressure Research in Mineral Physics, Geophys. Monogr. Ser., vol. 39, edited by M. H. Manghnani and Y. Syono, pp. 439-446, AGU, Washington, D.C., 1987.

Weidner, D. J., and N. Hamaya, Elastic properties of the olivine and spinel polymorphs of $\mathrm{Mg}_{2} \mathrm{GeO}_{4}$ and evaluation of elastic analogues, Phys. Earth Planet. Inter., 99, 275-283, 1983.

Weidner, D. J. and E. Ito, Elasticity of $\mathrm{MgSiO}_{3}$ in the ilmenite phase, Phys. Earth Planet. Inter., 40, 65-70, 1985.

Weidner, D.J., J. D. Bass, and M. T. Vaughan, The effect of crystal structure and composition on elastic properties of silicates, in High-Pressure Research in Geophysics, edited by S. Akimoto and M. H. Manghnani, pp. 123-133, D. Reidel, Hingham, Mass., 1982.

Weidner, D. J., H. Sawamoto, and S. Sasaki, Single-crystal elastic properties of the spinel phase of $\mathrm{Mg}_{2} \mathrm{SiO}_{4}, J$. Geophys. Res., 89, 7852-7859, 1984.

Weidner, D. J., A. Yeganeh-Haeri, and E. Ito, Elastic properties of majorite (abstract), Eos Trans. $A G U, 68,410,1987$.

Wolf, G. H., and M. S. Bukowinski, Theoretical study of the structural and thermoelastic properties of $\mathrm{MgSiO}_{3}$ and $\mathrm{CaSiO}_{3}$ perovskites: Implications for lower mantle composition, in High-Pressure Research in Mineral Physics, Geophys. Monogr. Ser., vol. 39, edited by M. H. Manghnani and Y. Syono, pp. 313-331, AGU, Washington, D.C., 1987.

Yagi, T., M. Akaogi, O. Shimomura, H. Tamai, and S. Akimoto, High pressure and high temperature equations of state of majorite, in High-Pressure Research in Mineral Physics, Geophys. Monogr. Ser., vol. 39, edited by M. Manghnani and Y. Syono, pp. 141-147, AGU, Washington, D.C., 1987.

Yeganeh-Haeri, A., and M. T. Vaughan, Single-crystal elastic constants of olivine (abstract), Eos Trans. AGU, 65, 282, 1984.

D. L. Anderson and T. S. Duffy, Seismological Laboratory, California Institute of Technology, Pasadena, CA 91125.

(Received November 12, 1987;

revised October 14, 1988;

accepted September 8, 1988.) 